\title{
Productivity Growth, On-the-Job Search, and Unemployment*
}

\author{
Hiroaki Miyamoto ${ }^{\dagger}$ \\ International University of Japan \\ Yuya Takahashi \\ University of Mannheim
}

First Version: May 2008

This Version: November 2010

\begin{abstract}
This paper studies the impact of long-run productivity growth on job finding and separation rates, and thus the unemployment rate, using a search and matching model. We incorporate disembodied technological progress and on-the-job search into the endogenous job separation model of Mortensen and Pissarides (1994). The incorporation of on-the-job search allows faster growth to reduce unemployment by decreasing the separation rate and inducing job creation. We demonstrate that introducing on-the-job search substantially improves the ability of the Mortensen and Pissarides model to explain the impact of growth on unemployment. Our quantitative analysis shows that our model increases the magnitude of the negative impact of growth on unemployment compared to the standard matching model with disembodied technological progress.
\end{abstract}

JEL Classification: E24; J64; O40

Keywords: Growth; Unemployment; Search-matching model; On-the-job search

\footnotetext{
${ }^{*}$ We are grateful to Steven Durlauf, John Kennan, Rasmus Lentz, Yoshimasa Shirai, and Shintaro Yamaguchi for their invaluable comments and suggestions. We also thank James Albrecht, Julen Esteban-Pretel, Junichi Fujimoto, Ryoichi Imai, Rebecca Lessem, John Morrow, Michael Rapp, Jiao Shi, and Susan Vroman and seminar participants at ISER at Osaka University, Search Theory Conference II at Osaka University, and the Public Economics Seminar at Keio University for their helpful comments. This paper was awarded the 11th ISER-Moriguchi Prize. All remaining errors are ours. Part of this research was supported by the Grants-in-Aid for Young Scientists of the Japan Society for the Promotion of Science (Kakenhi No. 22730164).

${ }^{\dagger}$ Corresponding Address: Hiroaki Miyamoto, hmiyamot@iuj.ac.jp, 777 Kokusai-cho, Minami Uonuma-shi, Niigata 949-7277 JAPAN, TEL., +81-25-779-1464.
} 


\section{Introduction}

This paper studies the effect of long-run productivity growth on unemployment, focusing on worker flows. Data from the US shows that productivity growth reduces unemployment by increasing the job finding rate and reducing the separation rate. On the other hand, empirical studies find that a large fraction of workers who leave their jobs move immediately to new jobs without entering unemployment (Fallick and Fleischman, 2004; Nagypál, 2005). This suggests that job-to-job flows are key to understanding unemployment dynamics. In order to study the impact of growth on unemployment, it is necessary to use a model in which workers' transitions between unemployment, employment, and across jobs are endogenously determined.

Following Mortensen and Pissarides (1994), we consider a search and matching model with endogenous job separation. In order to study the impact of long-run productivity growth on unemployment, we introduce disembodied technological progress (henceforth DTP), as in Pissarides (2000) and Pissarides and Vallanti (2007). Our model differs from the standard search and matching model with DTP with respect to job search and job separation. First, we allow for search by employed workers. Jobs differ by idiosyncratic productivity level, and the heterogeneity in productivity motivates on-the-job search. Second, in contrast with the standard model with DTP in which the separation rate is exogenous and assumed to be constant over time, in our model job separation is endogenously determined.

On-the-job search allows faster growth to reduce unemployment by increasing job creation and decreasing job separation. When the productivity growth rate rises, on-the-job search generates more vacancies by accelerating the reallocation of workers. Specifically, when growth accelerates, the search effort of employed workers rises, making it easier for firms to find a worker, which increases the value of new jobs. This induces more job creation and lowers unemployment. Furthermore, on-the-job search reduces job separation by increasing the value of the firm-worker match when the growth rate rises. In the model, workers in firms with low productivity jobs search for better jobs. Since the worker shares some of the expected benefit of search with the firm through the wage, the job becomes more resistant to negative shocks, leading to lower job separation.

Incorporating endogenous job separation and on-the-job search substantially improves the ability of the standard matching model with DTP to account for the size of the impact of growth on unemployment. Recently, Pissarides and Vallanti (2007) demonstrate that the matching model with DTP fails to explain the magnitude of the impact of growth on unemployment. Specifically, in the standard matching model with DTP and exogenous job separation, a $1 \%$ decrease in the growth rate increases unemployment by about $0.01 \%$, assuming Nash bargaining over wages. This 
is far from the estimated magnitude in the empirical literature. Blanchard and Wolfers (2000) estimate that a $1 \%$ decline in the growth rate leads to $0.25 \%-0.7 \%$ increase in the unemployment rate. Pissarides and Vallanti (2007) find the effect to be $1.3 \%$ to $1.5 \%$. After calibrating our model, we find that a one percentage point decline in productivity growth increases the unemployment rate by $0.32 \%$. The magnitude of the effect is short of that documented in the literature, but is much closer than the one generated by the standard model.

It is important to emphasize that neither endogenous job separation nor on-the-job search could alone explain the observed facts and generate the same magnitude. Without endogenous job separation, we cannot consider the impact of productivity growth on the separation rate. Without on-the-job search, faster growth is more likely to increase job separation, and thus unemployment. This shortcoming of the endogenous job separation model with DTP is also demonstrated by Prat (2007). With endogenous job separation, employed workers have better outside opportunities and so ask for higher wages when productivity growth increases. Since this outside option effect reduces the expected lifetime of jobs, faster productivity growth is more likely to increase the separation rate. However, since on-the-job search reduces the size of the outside option effect, in our model faster growth reduces job separation, lowering unemployment.

Related Literature: The search and matching theory predicts that the impact of productivity growth on unemployment depends on the extent to which new technology is embodied in new jobs (Mortensen and Pissarides, 1998; Pissarides and Vallanti, 2007). The standard search and matching model with disembodied technological progress predicts that a faster rate of productivity growth reduces unemployment through the so called capitalization effect (Pissarides, 2000 , chapter 3). On the other hand, in the model with embodied technological progress, faster productivity growth increases unemployment through creative destruction (Aghion and Howitt, 1994, 1998; Postel-Vinay, 2002). Motivated by the empirical evidence that productivity growth decreases the unemployment rate, Pissarides and Vallanti (2007) demonstrate that totally disembodied technology is necessary for the model to match empirical evidence. In this paper, we follow Pissarides and Vallanti (2007), and study the effect of DTP on labor market dynamics. Prat (2007) studies the impact of DTP on unemployment in a matching model with endogenous job separation. He demonstrates that under plausible parameter values, faster productivity growth increases the unemployment rate due to the outside option effect. By introducing on-thejob search, we find that productivity growth decreases unemployment in a search and matching model with endogenous job separation. Fujimoto (2009) studies the impact of DTP on unemployment by allowing productivity growth to be of a general or match-specific nature. Our study has some in common with his study: faster growth reduces job separation and hence the un- 
employment by making worker's outside option less attractive. While he focuses on the role of match-specific productivity growth, this study focuses on the role of the on-the-job search.

Our paper focuses on the impact of productivity growth on the labor market using on-the-job search in the search and matching model. A number of studies develop a matching model with onthe-job search. Pissarides (1994) and Krause and Lubik (2006) consider a matching model with two types of jobs (good and bad) to study the search activity of employed workers in bad jobs. In this paper, we allow for a continuum of job quality instead of just two discrete types. Mortensen (1994) introduces on-the-job search into the endogenous job separation model of Mortensen and Pissarides (1994). Mortensen (1994) demonstrates that on-the-job search helps to explain the negative correlation between job creation and destruction over the business cycle. In his model, workers employed by lower productivity firms search for better jobs. Thus, employed search varies through changes in the number of job seekers, not through the intensity of search. The set up of Nagypál (2007) is the most similar to this paper. In her model, heterogeneity in job amenity motivates search by employed workers, while in our model, heterogeneity in productivity plays this role. Furthermore, none of these papers discusses the impact of productivity growth on labor market dynamics or considers the long-run properties of worker reallocation, which is the main focus of this study. Michau (2007) also unveils that productivity growth induces a flow of job-to-job transitions and a reallocation of workers from low to high productivity jobs. While he considers a matching model with embodied technological progress, our paper studies the role of on-the-job search in a matching model with disembodied technological progress.

This paper provides empirical evidence on the long-run relationships between productivity growth, the unemployment rate, and rates of worker flows in the U.S. labor market. Recently, several studies investigate the contributions of inflows and outflows to unemployment dynamics. Shimer (2007) and Fujita and Ramey (2007) study the cyclical behavior of job finding and separation rates. They also measure the contributions of fluctuations in job finding and separation to the variability of unemployment in the U.S. economy. Similarly, Petrongolo and Pissarides (2008) study the contribution of inflows and outflows to unemployment in European countries. While they focus on labor market dynamics over the business cycle, in this paper we investigate its long-run properties.

The remainder of the paper is organized as follows. Section 2 presents salient features of the U.S. aggregate labor market in the long-run, and discusses the relationship between productivity growth and the labor market. Section 3 describes the theoretical model. We develop a generalized Mortensen and Pissarides model with on-the-job search. In Section 4 we characterize the steadystate equilibrium of the model. In Section 5, we calibrate the model parameters and present the results of quantitative comparative statics exercises. Section 6 discusses the sensitivity of 
the numerical results to our choice of parameter values. We also assess whether or not the results of our model crucially depends on the incorporation of on-the-job search. Conclusions and suggestions for future research are presented in Section 7.

\section{U.S. labor market facts}

In this section, we present some of the salient features of the U.S. aggregate labor market in the long-run. We use this to discuss the relationship between productivity growth and labor market variables. We focus on productivity growth, $g$, and three labor market variables: the unemployment rate $u$, the job finding rate $f$, and the separation rate $s$.

Labor productivity growth is measured by the first difference of logged labor productivity. We use real output per person in the non-farm business sector as labor productivity. The Bureau of Labor Statistics (BLS) constructs this quarterly time series as part of its Major Sector Productivity and Costs program. Using output per hour or total factor productivity as a measure of labor productivity yields similar results, but we use this series because it is a natural way to consider productivity in the standard search and matching model. Unemployment rate is the quarterly average of seasonally adjusted monthly data constructed by the BLS using the Current Population Survey (CPS) data.

Dynamics of the unemployment rate are determined by the underlying flows into and out of unemployment, particularly by the rates at which workers match with and separate from jobs. In this paper, we define the job finding rate as the rate of transition from unemployment to employment, and the separation rate as the rate of transition from employment to unemployment. Shimer (2007) uses short-term unemployment data and total unemployment data to pin down these rates. Following Shimer's (2007) time aggregation correction, we measure job finding and separation rates from the CPS over the 1948Q1-2005Q1 period.

Since our focus is the long-run relationship between productivity growth, unemployment rate, and rates of worker flows, we use band-pass filtering to smooth the data. The band-pass filter is a linear filter which retains the cyclical components of each series within a specific band of frequency and removes other components. By using the band-pass filter, we can isolate the longterm components of productivity growth and labor market variables. Let $y_{t}$ be a quarterly time series, and let $y_{t}^{*}$ denote its trend. Following Staiger et al. (2001), $y_{t}^{*}$ is estimated by passing $y_{t}$ through a two-sided low pass filter, with a cutoff frequency of 15 years. ${ }^{1}$ Essentially, this

\footnotetext{
${ }^{1}$ We also adopt the definition of the business cycle as the cyclical components between 1.5 years and 8 years, following Baxter and King (1999) and Stock and Watson (1999). When we use these limits as the definition of the business cycle, we get similar results.
} 
estimates $y_{t}^{*}$ as a long two-sided weighted moving average of $y_{t}$ with weights that sum to one. Estimates of the trend at the beginning and end of the sample are obtained by extending the series with autoregressive forecasts and backcasts of $y_{t}$, constructed from an estimated $\operatorname{AR}(4)$ model for the first difference of $y_{t}$.

Figure 1 presents quarterly time series data and their estimated trends for (a) labor productivity growth, (b) the unemployment rate, (c) the job finding rate, and (d) the separation rate. Table 1 summarizes the relationship among smoothed series of these four variables. ${ }^{2}$

Figure 1 and Table 1 show that productivity growth and the unemployment rate have a negative correlation. In Figure 2, we reproduce the smoothed series for these two variables. The smoothed series move closer together until the early 1960s, then apart during the 1970s, and then come slowly back to near their starting levels. The correlation between these two series during the sample period is -0.659 . Thus, there is a strong negative relationship between productivity growth and the unemployment rate at low frequencies. This finding confirms the empirical evidences from previous studies. ${ }^{3}$ The negative relationship between growth and unemployment is predicted by Pissarides (2000) and Pissarides and Vallanti (2007).

Figures 1-(c) and 1-(d) show smoothed series for job finding and separation rates. The job finding rate is large, averaging 27 percent during the sample period. In contrast, the separation rate is low and averaged 1.5 percent. The separation rate moved upward in the 1960's and 1970's and downwards afterwards. It is important to note that the separation rate moves positively with the unemployment rate and negatively with productivity growth. The correlation between the separation rate and unemployment rate is 0.854 . The correlation between the separation rate and productivity growth is -0.842 . On the other hand, the job finding rate is negatively correlated with the unemployment rate and the correlation is -0.841 . We can also see the positive relationship between the job finding rate and productivity growth. Their correlation is 0.310 .

To calculate the effect of productivity growth on labor market variables, following earlier studies (see for example, Pissarides and Vallanti, 2007), we employ the linear specification that

\footnotetext{
${ }^{2}$ For comparison purpose, we also use the Hodrick and Prescott (1997) filtering (henceforth HP filter) to smooth the data and get similar results. However, using the HP filter is not suitable for the analysis of the long run components of an economic series. The HP filter is best interpreted as a high-pass filter isolating frequencies of 8 years and higher in economic data and is not intended for other frequencies. Moreover, although the HP filter produces cyclical components that are covariance stationary for raw series that are integrated up to order four, the trend component of it reflects the non-stationarirty of the raw data.

${ }^{3}$ Staiger et al. (2001) find a strong negative relationship between productivity growth and the unemployment rate in the U.S. economy. Muscatelli and Tirelli (2002) find a negative correlation between these two variables for Japan, Germany, Italy, France, and Canada. Pissarides and Vallanti (2007) also find a negative relationship between total factor productivity (TFP) growth and unemployment in the US, Japan and European countries. See also Bruno and Sachs (1985), Ball and Moffitt (2001), and Tripier (2006).
} 

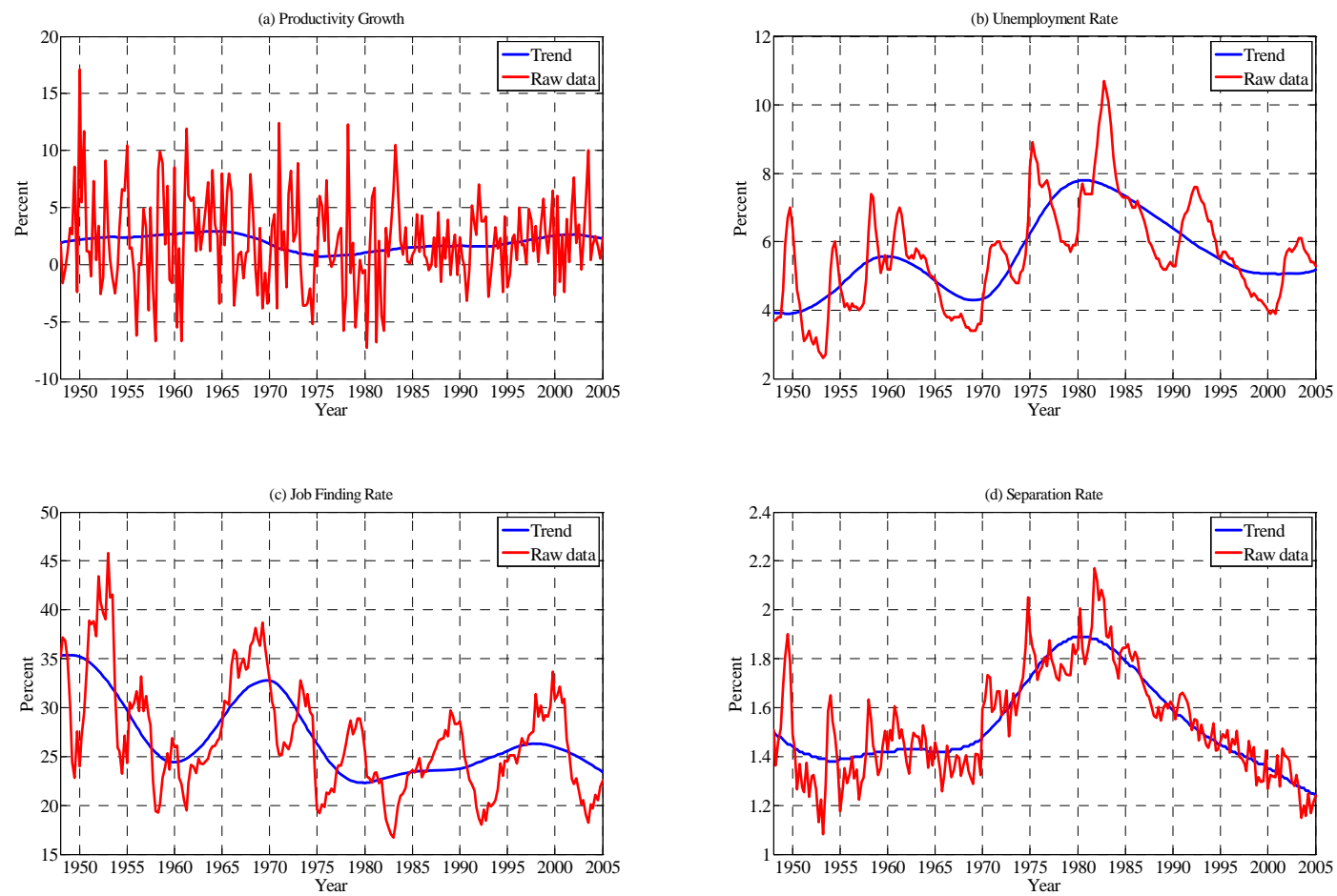

Figure 1: Macro series and their trend values.

Note: The rate of labor productivity growth is measured by the first difference of logged labor productivity. Labor productivity is real output per person in the non-farm business sector, constructed by the BLS Major Sector Productivity and Costs program. The unemployment rate is a quarterly average of the seasonally adjusted monthly series constructed by the BLS from the CPS. The job finding and the separation rates are constructed by Shimer (2007). See Shimer (2007) for data construction details. The trends are estimated by passing raw time series data through a two-sided low pass filter, with a cutoff frequency corresponding to 15 years. Sample covers 1948Q1-2005Q1. 


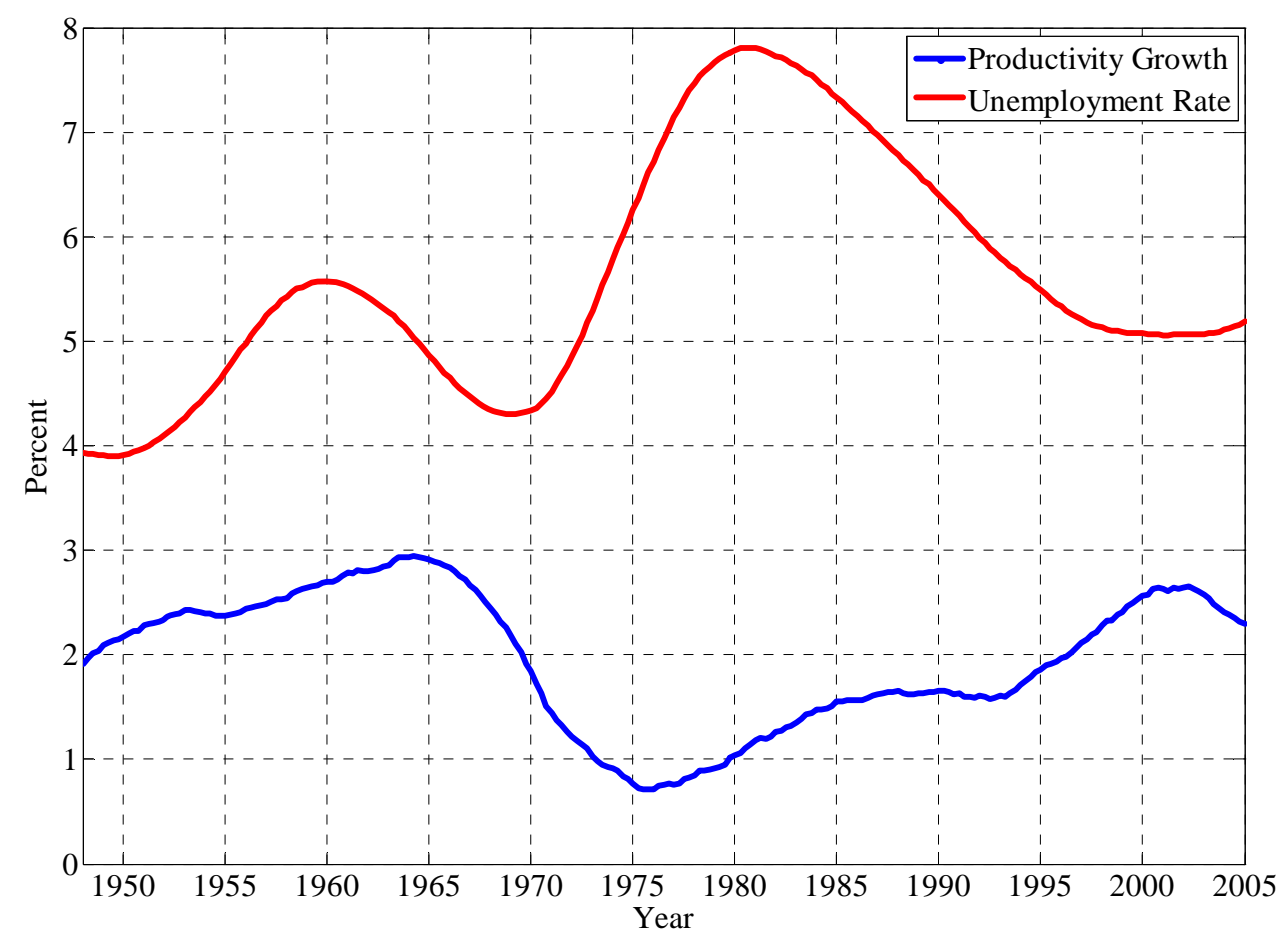

Figure 2: Productivity growth and unemployment rate.

Note: The dashed line indicates the trend of the productivity growth rate. The solid line indicates the trend of the unemployment rate. The rate of labor productivity growth is measured by the first difference of logged labor productivity. Labor productivity is real output per person in the nonfarm business sector, constructed by the BLS Major Sector Productivity and Costs program. The unemployment rate is a quarterly average of the seasonally adjusted monthly series constructed by the BLS from the CPS. The trends are estimated by passing raw time series data through a two-sided low pass filter, with a cutoff frequency corresponding to 15 years. Sample covers 1948Q1-2005Q1. 
relates long-run labor market variables to long-run productivity growth:

$$
x_{t}=\beta_{0}+\beta_{1} g_{t}+\varepsilon_{t},
$$

where $x_{t}$ is long-run labor market variables (the unemployment rate $(u)$, the job-finding rate $(f)$, and the separation rate $(s)), g_{t}$ is the long-run productivity growth rate, $\beta_{0}$ and $\beta_{1}$ are parameters and $\varepsilon_{t}$ is well-behaved stochastic disturbance. By using the estimated trends for productivity growth and labor market variables, we have the following OLS estimates for equation:

$$
\begin{aligned}
& u_{t}=\underset{(0.18)}{7.86}-\underset{(0.09)}{1.15} g_{t}+\hat{\varepsilon}_{t}, \quad R^{2}=0.44 \\
& f_{t}=\underset{(0.76)}{23.35}+\underset{(0.37)}{1.81} g_{t}+\hat{\varepsilon}_{t}, \quad R^{2}=0.10
\end{aligned}
$$

and

$$
s_{t}=\underset{(0.02)}{1.99}-\underset{(0.09)}{0.23} g_{t}+\hat{\varepsilon}_{t}, \quad R^{2}=0.71
$$

where standard errors are reported in parentheses. The estimates of these simple models demonstrate that (i) there is a negative relationship between productivity growth and the unemployment rate in the long-run, (ii) there is a positive relationship between productivity growth and the job finding rate, and (iii) there is a negative relationship between productivity growth and the separation rate. A $1 \%$ fall in the long-run productivity growth rate increases the unemployment rate by $1.15 \%$. This finding confirms the empirical evidences from previous studies, estimating magnitude of the impact of growth on unemployment. A $1 \%$ fall in the long-run growth rate reduces the job finding rate by $1.81 \%$, and increases the separation rate $0.23 \%$.

We have seen that the job finding rate co-moves negatively with the unemployment rate and the separation rate co-moves positively with the unemployment rate in the long-run. Now we quantify the contributions of separation and job finding rates to overall unemployment variability in the long-run following Shimer (2007) and Fujita and Ramey (2007). To analyze how hazard rates affect unemployment variability, Shimer (2007) and Fujita and Ramey (2007) approximate the unemployment rate using the theoretical steady-state value associated with the contemporaneous job finding and separation rates. Thus,

$$
u_{t} \simeq \frac{s_{t}}{s_{t}+f_{t}} \equiv \tilde{u}_{t}
$$

where $u_{t}$ is the unemployment rate, $s_{t}$ is the the separation rate, and $f_{t}$ is the job finding rate. Let $\bar{f}$ and $\bar{s}$ denote the average value of $f_{t}$ and $s_{t}$ during the sample period. Then we compute the hypothetical unemployment rates

$$
u_{t}^{F} \equiv \frac{\bar{s}}{\bar{s}+f_{t}} \text { and } u_{t}^{S} \equiv \frac{s_{t}}{s_{t}+\bar{f}}
$$




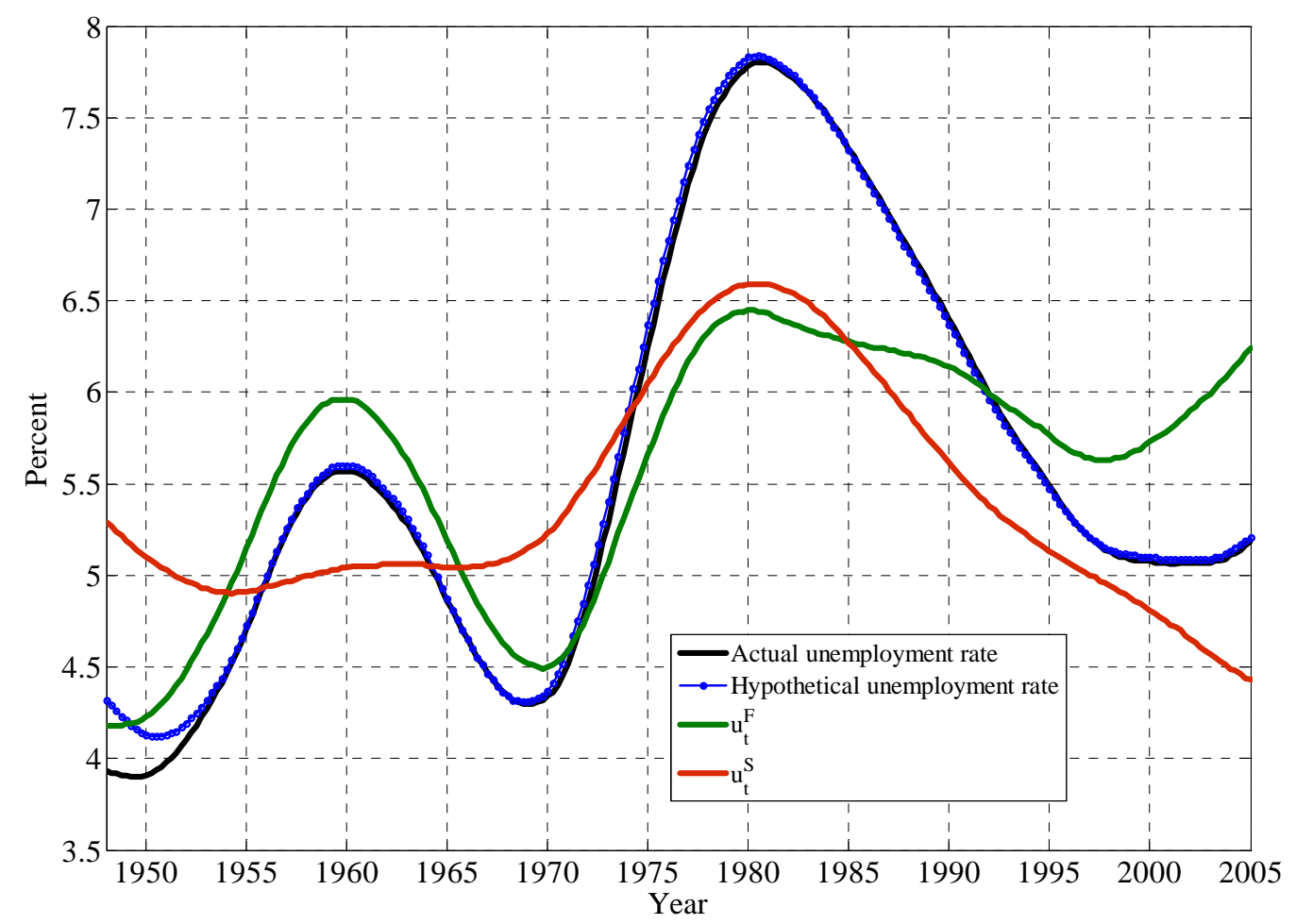

Figure 3: Contribution of unemployment rate variability.

Note: The solid line indicates the actual unemployment rate. The line with circle indicates hypothetical unemployment rate $\tilde{u}$. The dashed line indicates the hypothetical unemployment rate if there were only fluctuations in the job finding rate $u^{F}$. The dash-dotted line indicates the hypothetical unemployment rate with only fluctuations in the separation rate $u^{S}$. See text for definitions of $\tilde{u}, u^{F}$ and $u^{S}$. The unemployment rate is a quarterly average of the seasonally adjusted monthly series constructed by the BLS from the CPS. Sample covers 1948Q1-2005Q1. 
as measures of the contributions of fluctuations in the job finding and employment exit rates to overall fluctuations in the unemployment rate.

Figure 3 plots hypothetical unemployment rates $\tilde{u}_{t}, u_{t}^{F}$ and $u_{t}^{S}$ together with the actual unemployment rate. Figure 3 shows that both the job finding rate and the separation rate tend to move with the unemployment rate.

To quantify the contribution of separation and job finding rates to overall unemployment variability, we look at the co-movement of long-run components of the data. Over the sample period, the covariance of the cyclical component of $u_{t}$ and $u_{t}^{F}$ accounts for about half of the variance of the cyclical component of $u_{t}$. Similarly, cyclical fluctuations in the separation rate explain 47 percent of the fluctuation in the unemployment rate. This suggests that the job finding rate and the separation rate account for roughly similar proportions of overall unemployment variability in the long-run.

Since both job finding and separation rates contribute to variability in unemployment in the long-run, the fact that the job finding rate is positively correlated with productivity growth seems to support the capitalization effect theory of Pissarides (2000). Furthermore, the negative correlation between the separation rate and productivity growth suggests a new channel for productivity growth to affect unemployment, which has not been pointed out in the literature.

\section{The model}

We consider a search and matching model with endogenous job separation, in the spirit of Mortensen and Pissarides (1994). We allow for search by employed workers. Jobs differ by idiosyncratic productivity level, and the heterogeneity in productivity motivates on-the-job search. Furthermore, in order to study the impact of productivity growth on labor market dynamics, we introduce disembodied technological progress, as in Pissarides (2000) and Pissarides and Vallanti (2007).

There is a large measure of ex-ante identical firms and a unit measure of ex-ante identical workers. Both workers and firms are infinitely lived and maximize the present discounted value of income with discount rate $r$. Time is continuous.

Firms are free to enter the market and post a vacancy at flow cost $\gamma_{t}$ in order to recruit a worker. If a firm succeeds in recruiting a worker, the firm starts to produce output and the worker earns an endogenous wage $w_{t}$. An employed worker is allowed to search for other jobs. The firm-worker pair continues to produce output until the match is destroyed by a negative productivity shock or if the worker finds a better job. An unemployed worker receives a flow utility $z_{t}$ and searches for a job. 
Both unemployed and employed workers can choose to search for a new job at a flow $\operatorname{cost} c_{t}(e)$, where $e$ is the search effort and $c_{t}(e)$ is a strictly increasing, strictly convex, twice continuously differentiable function with $c_{t}(0)=c_{t}^{\prime}(0)=0$. Workers exerting search effort $e$ encounter new job opportunities at the Poisson rate $\theta q(\theta) e$, where $\theta q(\theta)$ is the matching rate per unit of search intensity that will be defined later.

Production technology Production takes place when one firm is matched with one worker. Let the output of each firm at time $t$ be given by $p_{t} x$, where $p_{t}$ is a general productivity parameter which is common to all producing jobs, and $x$ is an idiosyncratic productivity specific to each job. Suppose that the leading technology in the economy is driven by an exogenous invention process that grows at the rate $g<r$, so

$$
p_{t}=p_{0} \exp (g t)
$$

where $p_{0}>0$ is some initial productivity level which is normalized to be one.

The initial value of idiosyncratic productivity is drawn from a distribution $F:\left[\underline{x}_{F}, \bar{x}_{F}\right] \rightarrow$ $[0,1]$. Subsequently, let $\left\{x_{t}\right\}$ be a jump process characterized by arrival rate $\lambda$ and a distribution of new realizations $G:\left[\underline{x}_{G}, \bar{x}_{G}\right] \rightarrow[0,1]$.

Matching technology There is a single matching function that determines the number of meetings between workers and firms, as a function of the total amount of search effort of workers, $\bar{e}$, and the number of vacancies posted, $v$ :

$$
m_{t}=m\left(v_{t}, \bar{e}_{t}\right)
$$

The matching function $m(v, \bar{e})$ is continuous, twice differentiable, increasing in its arguments and exhibits constant returns to scale. The meeting rate per unit of vacant jobs is

$$
q\left(\theta_{t}\right)=\frac{m\left(v_{t}, \bar{e}_{t}\right)}{v_{t}}=m\left(1, \frac{1}{\theta_{t}}\right)
$$

where

$$
\theta_{t} \equiv \frac{v_{t}}{\bar{e}_{t}}
$$

is labor market tightness at time $t$. Then, the meeting rate per unit of search effort for workers is

$$
\theta_{t} q\left(\theta_{t}\right)=\frac{m\left(v_{t}, \bar{e}_{t}\right)}{\bar{e}_{t}}=m\left(\frac{v_{t}}{\bar{e}_{t}}, 1\right)
$$


Rendering the growth model stationary We focus on the steady state. This corresponds to a balanced growth path where the economy grows at the rate of disembodied technological progress $g$. To make the model stationary, we assume that all exogenous variables grow at the rate of disembodied technological progress $g .{ }^{4}$ Thus, we define two positive exogenous parameters $z$ and $\gamma$ such that $z_{t}=p_{t} z$ and $\gamma_{t}=p_{t} \gamma$. Furthermore, the search cost function can be rewritten as $c_{t}(e)=p_{t} c(e)$.

\subsection{Value functions}

The values of workers and firms at time $t$ are described by a series of Bellman equations. We start with the worker's side. Let the value for an employed worker in a job with idiosyncratic productivity $x$ be $W_{t}(x)$ and the value of an unemployed worker at time $t$ be $U_{t}$.

The value of an employed worker in a job with productivity $x$ is characterized by the following Bellman equation:

$$
\begin{aligned}
r W_{t}(x)= & \max _{e \geq 0}\left\{w_{t}(x)-p_{t} c(e)+\lambda \int\left(\max \left[W_{t}\left(x^{\prime}\right), U_{t}\right]-W_{t}(x)\right) d G\left(x^{\prime}\right)\right. \\
& \left.+e \theta_{t} q\left(\theta_{t}\right) \int_{\underline{x}}^{\bar{x}} \mathbb{I}\left\{W\left(x^{\prime}\right)>W(x)\right\}\left[W_{t}\left(x^{\prime}\right)-W_{t}(x)\right] d F\left(x^{\prime}\right)+\dot{W}_{t}(x)\right\} .
\end{aligned}
$$

In equation (1), $\mathbb{I}\{\cdot\}$ is an indicator function that equals one if its expression is true and equals zero otherwise. The value of an employed worker in a job with productivity $x$ is determined by several factors. The worker receives wage $w(x)$. The match draws a new value of idiosyncratic productivity at rate $\lambda$, in which case the worker loses the current asset value $W(x)$ and gains the asset value associated with working at the new productivity level $x^{\prime}$ or being unemployed, whichever is greater. Moreover, the worker optimally chooses his search intensity at cost $p c(e)$ and obtains the benefit of meeting new job opportunities at rate $e \theta q(\theta)$. If the worker encounters a new firm, he accepts any job that has a higher asset value $W\left(x^{\prime}\right)$ than the current asset value $W(x)$. Finally, the asset value of a match is expected to change over time due to exogenous technological progress.

The value of an unemployed worker is

$$
r U_{t}=\max _{e}\left\{p_{t} z-p_{t} c(e)+e \theta_{t} q\left(\theta_{t}\right) \int\left(\max \left[W_{t}(x), U_{t}\right]-U_{t}\right) d F(x)+\dot{U}_{t}\right\} .
$$

An unemployed worker also chooses his search effort $e$ at cost $p_{t} c(e)$.

\footnotetext{
${ }^{4}$ In the literature, in order to ensure the existence of a balanced growth path, usually all the exogenous variables are assumed to follow the pace of productivity growth. See, for example, Mortensen and Pissarides (1999) and Pissarides and Vallanti (2007).
} 
We now turn to the side of a firm. Let $\Pi_{t}(x)$ denote the asset value for a firm with a filled job with idiosyncratic productivity $x$. Denote the optimal search intensity of an employed worker in a job with productivity $x$ by $e(x)$. The value of a filled job with an idiosyncratic productivity $x$ satisfies

$$
\begin{aligned}
r \Pi_{t}(x)= & p_{t} x-w_{t}(x)+\lambda \int\left(\max \left[\Pi_{t}\left(x^{\prime}\right), V_{t}\right]-\Pi_{t}(x)\right) d G\left(x^{\prime}\right) \\
& +e(x) \theta_{t} q\left(\theta_{t}\right) \int_{\underline{x}}^{\bar{x}} \mathbb{I}\left\{W\left(x^{\prime}\right)>W(x)\right\}\left[V_{t}-\Pi_{t}(x)\right] d F\left(x^{\prime}\right)+\dot{\Pi}_{t}(x),
\end{aligned}
$$

where $V_{t}$ is the value of posting a vacancy. A firm with a filled job receives flow revenues $p x-w(x)$, which is the productive output of the match minus the wage paid to the worker. The match draws a new value of idiosyncratic productivity at rate $\lambda$. Facing the changed productivity, the firm decides to continue producing if $\Pi\left(x^{\prime}\right)$ is larger than the value of a vacant job. The job may be destroyed by the quit of the worker at rate $e(x) \theta q(\theta) \int_{\underline{x}}^{\bar{x}} \mathbb{I}\left\{W\left(x^{\prime}\right)>W(x)\right\} d F\left(x^{\prime}\right)$, in which case the firm loses its asset value. Finally, the asset value of a match is expected to change over time due to exogenous technological progress.

The firm that has a job with value $\Pi_{t}(x)$ at time $t$ expects to make a capital gain of $d \Pi_{t} / d t=$ $g \Pi$ on it. The same holds for the value of an employed worker $W_{t}(x)$ and an unemployed worker $U_{t}$, where the capital gain is $g W(x)$ and $g U$, respectively. But the value of a vacant job $V_{t}$, because it is zero by the free entry condition, does not change. Replacing the capital gain by its steady-state value, the above Bellman equations can be rewritten as follows:

$$
\begin{aligned}
&(r-g) W(x)= \max _{e \geq 0}\left\{w(x)-p c(e)+\lambda \int\left(\max \left[W\left(x^{\prime}\right), U\right]-W(x)\right) d G\left(x^{\prime}\right)\right. \\
&\left.+e \theta q(\theta) \int_{\underline{x}}^{\bar{x}} \mathbb{I}\left\{W\left(x^{\prime}\right)>W(x)\right\}\left[W\left(x^{\prime}\right)-W(x)\right] d F\left(x^{\prime}\right)\right\}, \\
&(r-g) U=\max _{e}\left\{p z-p c(e)+e \theta q(\theta) \int(\max [W(x), U]-U) d F(x)\right\},
\end{aligned}
$$

and

$$
\begin{aligned}
(r-g) \Pi(x)= & p x-w(x)+\lambda \int\left(\max \left[\Pi\left(x^{\prime}\right), V\right]-\Pi(x)\right) d G\left(x^{\prime}\right) \\
& +e(x) \theta q(\theta) \int_{\underline{x}}^{\bar{x}} \mathbb{I}\left\{W\left(x^{\prime}\right)>W(x)\right\}[V-\Pi(x)] d F\left(x^{\prime}\right) .
\end{aligned}
$$

\subsection{Wage determination}

Wages are determined by the sharing of the surplus from the match, where the worker and the firm receive shares $\beta$ and $1-\beta$, respectively. It is assumed that wages can be revised continuously 
at no cost, so the long-run contracts are ruled out. ${ }^{5}$ Furthermore, we assume that matches cannot be recalled. Note that the outside option of the worker is unemployment. The timing assumption of the model is as follows. At each instant, first the worker decides the level of search intensity, in anticipation of the wage outcome, and then the surplus sharing takes place.

Because of the timing assumption of the model and the nature of bargaining, the wage cannot reduce the likelihood that a worker quits. Therefore, the non-convexity of the Pareto frontier discussed in Shimer (2006) does not arise in our model. In this model, at each instant a worker decides how much to search, in anticipation of the wage outcome, and then the surplus-sharing takes place. Thus, the surplus-sharing rule does not allow for the wage to influence the search behavior of the worker. This allows us to determine the wage as an outcome of Nash bargaining, since the feasible payoff set is convex. ${ }^{6}$

The key object for characterizing the model is the match surplus function. Let $S(x)$ be the joint gross return from a match with job-specific productivity $x$. Then the surplus function is

$$
S(x)=\Pi(x)+W(x)-U-V .
$$

Surplus sharing implies

$$
\Pi(x)-V=(1-\beta) S(x),
$$

and

$$
W(x)-U=\beta S(x) .
$$

Using of equations (3),(5), and (6), we obtain the equation characterizing $S(x)$, as follows:

$$
\begin{aligned}
(r+\lambda-g) S(x)= & p x-(r-g)[U+V]-p c(e(x))+\lambda \int_{\underline{x}}^{\bar{x}} \max \left[S\left(x^{\prime}\right), 0\right] d G\left(x^{\prime}\right) \\
& +e(x) \theta q(\theta) \int_{\underline{x}}^{\bar{x}} \mathbb{I}\left\{W\left(x^{\prime}\right)>W(x)\right\}\left[\beta S\left(x^{\prime}\right)-S(x)\right] d F\left(x^{\prime}\right) .
\end{aligned}
$$

Since $S(x)$ is strictly increasing in $x, W(x)$ and $\Pi(x)$ are also strictly increasing in $x$.Since $W(\cdot)$ is strictly increasing, the acceptance decisions of an unemployed worker has the reservation property. Thus, an unemployed worker accepts any job with productivity $x \geq R$, where $R$ is defined by

$$
W(R)=U \Leftrightarrow S(R)=0 .
$$

\footnotetext{
${ }^{5}$ Thus, even if an employed worker could start negotiations with a new employer before resigning from the current job, this would not affect the equilibrium outcome. The new employer would immediately renegotiate the wage once the worker breaks the relationship with the previous employer.

${ }^{6}$ It may be helpful to consider a discrete time version of the model to understand this argument. In the discrete time model, the search behavior of a worker is governed by returns to search that accrue in the next period. Thus, to reduce the probability that the worker quits, the firm should commit to higher wages in the future. However, with continuous renegotiation, such a commitment cannot be made. Therefore, under these assumptions, the payoff set is convex, and surplus sharing is equivalent to the Nash bargaining solution.
} 
Since the surplus function $S(\cdot)$ is strictly increasing, the firm and the worker will choose to adopt a reservation policy, i.e., they will continue their match if $S(x) \geq 0$ but stop if $S(x)<0$. Thus, a separation takes place at $x=R$. Note that the reservation productivity at the time the match is formed is the same as the one at match dissolution, even though the initial distributions of productivity differ.

\subsection{The search choice}

Since $W(x)$ is strictly increasing in $x$, an employed worker accepts all new jobs with a higher initial productivity than his current job. Thus,

$$
\int_{\underline{x}}^{\bar{x}} \mathbb{I}\left\{W\left(x^{\prime}\right)>W(x)\right\}\left[W\left(x^{\prime}\right)-W(x)\right] d F\left(x^{\prime}\right)=\int_{x}^{\bar{x}}\left[W\left(x^{\prime}\right)-W(x)\right] d F\left(x^{\prime}\right) \text { for } x<\bar{x} .
$$

Then, equation (3) can be rewritten as

$$
\begin{aligned}
(r-g) W(x)= & \max _{e \geq 0}\left\{w(x)-p c(e)+\lambda \int\left(\max \left[W\left(x^{\prime}\right), U\right]-W(x)\right) d G\left(x^{\prime}\right)\right. \\
& \left.+e \theta q(\theta) \int_{x}^{\bar{x}}\left[W\left(x^{\prime}\right)-W(x)\right] d F\left(x^{\prime}\right)\right\} .
\end{aligned}
$$

The optimal search intensity of an employed worker is found by using the equation (8). The first-order condition of $(8)$ is

$$
p c^{\prime}(e(x))=\theta q(\theta) \int_{x}^{\bar{x}}\left[W\left(x^{\prime}\right)-W(x)\right] d F\left(x^{\prime}\right)=\theta q(\theta) \beta \int_{x}^{\bar{x}}\left[S\left(x^{\prime}\right)-S(x)\right] d F\left(x^{\prime}\right) .
$$

Because the search cost function is strictly convex and $S(x)$ is strictly increasing, the optimal search effort by employed workers is strictly decreasing in $x$ for $x<\bar{x}$. Furthermore, by the convexity of $c(\cdot)$ and $c^{\prime}(0)=0, e(x)=0$ for $x \geq \bar{x}$.

The value function of an unemployed worker can be rewritten as

$$
(r-g) U=\max _{e}\left\{p z-p c(e)+e \theta q(\theta) \int_{R}^{\bar{x}}[W(x)-U] d F(x)\right\} .
$$

Denote the optimal search intensity of an unemployed worker by $e_{u}$. Then, the first-order condition of (10) yields

$$
-p c^{\prime}\left(e_{u}\right)+\theta q(\theta) \int_{R}^{\bar{x}}[W(x)-U] d F(x)=0 \Leftrightarrow p c^{\prime}\left(e_{u}\right)=\beta \theta q(\theta) \int_{R}^{\bar{x}} S(x) d F(x) .
$$

Under the assumption that the cost of search effort is the same between an employed worker and an unemployed worker, a comparison of equations (9) and (11) implies that the optimal search effort when unemployed equals the search effort when employed at $x=R$, i.e.,

$$
e_{u}=e(R) .
$$




\subsection{Vacancy creation}

The value of posting a vacancy is

$$
r V=-p \gamma+q(\theta) \int_{\underline{x}}^{\bar{x}}[\Pi(x)-V] \Theta(x) d F(x),
$$

where $\Theta(x)$ is the probability that a searching worker accepts a job with productivity $x$. This is the ratio of search effort by workers who are willing to accept a match with initial productivity $x$ to the total amount of search effort $\bar{e}$ exerted by all workers.

The measure of employed workers in jobs with an idiosyncratic productivity less then or equal to $x$ is denoted by $H(x)$. Thus, $H(x)$ is the distribution of employed workers.

The total amount of search effort $\bar{e}$ exerted by all workers is

$$
\bar{e}=u e_{u}+(1-u) \int_{R}^{\bar{x}} e\left(x^{\prime}\right) d H\left(x^{\prime}\right) .
$$

Then, the acceptance probability will be

$$
\Theta(x)=\left\{\begin{array}{cl}
\bar{e}^{-1}\left[u e_{u}+(1-u) \int_{R}^{x} e\left(x^{\prime}\right) d H\left(x^{\prime}\right)\right] & \text { if } x \geq R \\
0 & \text { if } x<R
\end{array} .\right.
$$

Free entry implies that the value of a vacancy is zero in equilibrium. Thus,

$$
V=0
$$

\subsection{Labor market dynamics}

The steady-state unemployment rate is determined by equating the flow into unemployment with the flow out of it. The flow into unemployment is equal to the number of employed workers who work in jobs that get hit by an idiosyncratic shock below the reservation value. Therefore the flow into unemployment is given by $\lambda G(R)(1-u)$. The flow out of unemployment is equal to the number of unemployed workers who find jobs. This is $\theta q(\theta) e_{u}[1-F(R)] u$. Then, the evolution of unemployment is given by

$$
\dot{u}=\lambda G(R)(1-u)-\theta q(\theta) e_{u}[1-F(R)] u,
$$

and its steady-state value is

$$
u=\frac{\lambda G(R)}{\lambda G(R)+\theta q(\theta) e_{u}[1-F(R)]} .
$$

To close the model, we need to derive the stationary distribution of employed workers across productivity levels. Denote the measure of employed workers in jobs with an idiosyncratic productivity less than or equal to $x$ by $H(x)$. The flow into this subset consists of unemployed and 
employed workers. The flow of unemployed workers who obtain a job with productivity $x$ or less is $\theta q(\theta) e_{u}[F(x)-F(R)] u$. Because of the idiosyncratic productivity shocks, employed workers who originally work in jobs with a productivity higher than $x$ may move to this subset, which is equal to $\lambda[G(x)-G(R)][H(\bar{x})-H(x)]$. Thus, the sum of them is the total flow into the set of employed workers in jobs with productivity $x$ or less. The flow out of this subset consists of three flows. First is those who lose their jobs after a productivity shock, equal to $\lambda G(R) H(x)$. Second is the flow of those whose jobs' productivity becomes higher than $x$ after the arrival of a productivity shock; this is equal to $\lambda H(x)[1-G(x)]$. Third is the flow of those who find jobs that have a higher productivity than their current jobs. Since the rate at which a worker searches depends on this current productivity, the flow that finds a job with productivity higher than $x$ is

$$
\theta q(\theta)[1-F(x)] \int_{R}^{x} e\left(x^{\prime}\right) d H\left(x^{\prime}\right) .
$$

Then, the stationary distribution of employed workers across idiosyncratic productivity is given by

$$
\begin{aligned}
& \theta q(\theta) e_{u}[F(x)-F(R)] u+\lambda[G(x)-G(R)][H(\bar{x})-H(x)] \\
= & \lambda G(R) H(x)+\lambda H(x)[1-G(x)]+\theta q(\theta)[1-F(x)] \int_{R}^{x} e\left(x^{\prime}\right) d H\left(x^{\prime}\right) .
\end{aligned}
$$

The measure of job-to-job transition is given by

$$
J J=(1-u) \int_{R}^{\bar{x}} \theta q(\theta) e(x)[1-F(x)] h(x) d x,
$$

so the quit rate is

$$
Q=\int_{R}^{\bar{x}} \theta q(\theta) e(x)[1-F(x)] h(x) d x .
$$

Since the flow of employment-to-unemployment transition is $\lambda G(R)(1-u)$, the separation rate, defined as the flow rate from employment to unemployment, is $\lambda G(R)$. Then, the job destruction rate is also $\lambda G(R)$.

The ratio of job-to-job to employment-to-unemployment transition is given by

$$
\frac{\int_{R}^{\bar{x}} \theta q(\theta) e(x)[1-F(x)] h(x) d x}{\lambda G(R)} .
$$

The stationary equilibrium is characterized by a constant unemployment rate, vacancy rate, and an invariant distribution of employed workers across productivity.

Definition 1 A stationary (stationarized balanced growth) equilibrium is a list of unemployment $u$, vacancy rate $v$, total search intensity $\bar{e}$, asset values $\{\Pi(x), W(x), V, U\}$, wage equation $w(x)$, search intensity of unemployed workers $e_{u}$, search intensity of employed workers $e(x)$, and a distribution of employed workers $H(x)$ such that 
- $W(\cdot)$ and $U$ are the value of employed workers and unemployed workers making optimal searching and matching decisions, given $u, v, \bar{e}, w(\cdot)$ and $H(\cdot) . e_{u}$ and $e(\cdot)$ are the corresponding optimal search effort policies,

- $\Pi(\cdot)$ and $V$ are the value of a filled job and a vacancy for firms making optimal vacancy creation decisions, given $u, v, \bar{e}, w(\cdot), e(\cdot)$ and $H(\cdot)$,

- Wages are determined by Nash bargaining, where workers and firms get shares $\beta$ and $1-\beta$ of the surplus, respectively, given $e(x)$,

- There is free entry of vacancies; thus $V=0$, and

- The distribution $H(\cdot)$, the unemployment rate $u$, the vacancy rate $v$, and the total search intensity $\bar{e}$ are consistent with decisions of agents in the economy.

\section{Characterization}

Because $S(x)$ and $W(x)$ are strictly increasing and the free entry condition $V=0$, equation $(7)$ can be rewritten as

$$
\begin{aligned}
(r+\lambda-g) S(x)= & p x-(r-g) U-p c(e(x))+\lambda \int_{R}^{\bar{x}} S\left(x^{\prime}\right) d G\left(x^{\prime}\right) \\
& +e(x) \theta q(\theta) \int_{x}^{\bar{x}}\left[\beta S\left(x^{\prime}\right)-S(x)\right] d F\left(x^{\prime}\right) .
\end{aligned}
$$

By substituting the value of an unemployed worker into equation (13), we have

$$
\begin{aligned}
(r+\lambda-g) S(x)= & p(x-z)+p c\left(e_{u}\right)-e_{u} \theta q(\theta) \beta \int_{R}^{\bar{x}} S\left(x^{\prime}\right) d F\left(x^{\prime}\right)-p c(e(x)) \\
& +\lambda \int_{R}^{\bar{x}} S\left(x^{\prime}\right) d G\left(x^{\prime}\right)+e(x) \theta q(\theta) \int_{x}^{\bar{x}}\left[\beta S\left(x^{\prime}\right)-S(x)\right] d F\left(x^{\prime}\right) .
\end{aligned}
$$

Evaluating (14) at $x=R$ and using the optimal separation rule $S(R)=0$, we have

$$
0=p(R-z)+\lambda \int_{R}^{\bar{x}} S\left(x^{\prime}\right) d G\left(x^{\prime}\right) .
$$

This equation implies that the difference between $R$ and $z$ comes from the option value of working. Since idiosyncratic shocks may increase the value of the match, a worker is willing to accept a job with low productivity.

From (14) and (15), we obtain

$$
\begin{aligned}
(r+\lambda-g) S(x)= & p(x-R)-p c(e(x))+p c(e(R))+e(x) \theta q(\theta) \int_{x}^{\bar{x}}\left[\beta S\left(x^{\prime}\right)-S(x)\right] d F\left(x^{\prime}\right) \\
& -e(R) \theta q(\theta) \int_{R}^{\bar{x}} \beta S\left(x^{\prime}\right) d F\left(x^{\prime}\right) .
\end{aligned}
$$


Differentiating with respect to $x$ on both sides of the surplus equation and invoking the envelope theorem give

$$
(r+\lambda+e(x) \theta q(\theta)[1-F(x)]-g) S^{\prime}(x)=p+(1-\beta) \theta q(\theta) S(x)\left\{e(x) f(x)-e^{\prime}(x)[1-F(x)]\right\} .
$$

Given a search intensity function $e(x)$, this is a first-order linear differential equation in $S(x)$. Note that since the differential equation has variable coefficients, it does not generally have a closed-form solution.

Since $e(x)=0$ for $x \geq \bar{x}$, equation (16) yields

$$
S^{\prime}(\bar{x})=\frac{p}{r+\lambda-g} .
$$

Totally differentiating the optimal search intensity condition (9) yields

$$
e^{\prime}(x)=\frac{-\theta q(\theta) \beta S^{\prime}(x)[1-F(x)]}{p c^{\prime \prime}(e(x))} .
$$

This is an ordinary differential equation for $e(x)$ with the boundary condition $e(\bar{x})=0$. Thus, now we have a system of equations for $S(x)$ and $e(x)$.

Differentiating equation (12) with respect to $x$ and rearranging yield

$$
H^{\prime}(x)=\frac{\theta q(\theta) e_{u} F^{\prime}(x) u+\lambda G^{\prime}(x)[1-u]+\frac{F^{\prime}(x)}{1-F(x)}\left\{\theta q(\theta) e_{u}[F(x)-F(R)] u+\lambda[G(x)-G(R)](1-u)-\lambda H(x)\right\}}{\lambda+\theta q(\theta)[1-F(x)] e(x)}
$$

with boundary condition

$$
H(R)=0 .
$$

This differential equation characterizes the distribution of employed workers.

The average wage in the economy is obtained by

$$
\bar{w}=\frac{\int_{R}^{\bar{x}} w(x) d H(x)}{1-u},
$$

where

$$
\begin{aligned}
w(x)= & \beta p x+(1-\beta) p c(e(x))-e(x) \theta q(\theta)(1-\beta) \beta \int_{\underline{x}}^{\bar{x}} S\left(x^{\prime}\right) d F\left(x^{\prime}\right) \\
& +(1-\beta)\left[p z-p c\left(e_{u}\right)+e_{u} \theta q(\theta) \beta \int_{R}^{\bar{x}} S(x) d F(x)\right]
\end{aligned}
$$

Then, the replacement rate in the model is $z / \bar{w}$. 


\section{Quantitative analysis}

In this section, we calculate the equilibrium of the above model using numerical methods, since it is not possible to solve analytically. First, we calibrate the model to match the several dimensions of the data. Then, we perform quantitative comparative statics exercises by calculating the steady-state response to an increase in the rate of disembodied technological growth.

\subsection{Basic calibration}

In order to investigate the quantitative impact of disembodied technological progress on unemployment, we calibrate the model to match U.S. labor market facts. The following 12 parameters have to be determined: the discount rate $r$, the level of productivity $p$, the value of leisure $z$, the worker's bargaining power $\beta$, two matching function parameters $m_{0}$ and $\alpha$, two search cost function parameters $c_{0}$ and $\mu$, the technological growth rate $g$, the arrival rate of idiosyncratic productivity shocks $\lambda$, the parameter in the idiosyncratic productivity distribution $\nu$, and the vacancy cost $\gamma$.

We choose the model period to be one-year and set the discount rate $r=0.05$ because the annual real interest rate has been around $5 \%$. Since the level of productivity does not influence the steady state, we normalize $p=1$ without loss of generality. For the benchmark case, we set $g$ to $2 \%$, the average productivity growth rate in the US from 1948 to 2007 .

We assume that the matching function is Cobb-Douglas,

$$
m(v, \bar{e})=m_{0} v^{1-\alpha} \bar{e}^{\alpha}
$$

where $m_{0}$ is the matching constant and $\alpha$ is the matching elasticity with respect to the total search effort of workers. Then, $\theta q(\theta)=m_{0} \theta^{1-\alpha}$ and $q(\theta)=m_{0} \theta^{-\alpha}$. Following Mortensen and Nagypál (2007), we choose the elasticity of the matching function to equal 0.5. ${ }^{7}$ We also set the workers' bargaining power $\beta$ to 0.5 .

The search cost function is specified by $c(e)=c_{0} e^{1+\mu}$, where $c_{0}$ is a scale parameter and $\mu>0$. Since the value of $c_{0}$ can be eliminated from the equilibrium condition, we set it to equal to 1 . This can be achieved by letting $\tilde{e}(x)=e(x) c_{0}^{1 /(1+\mu)}, \widetilde{\theta q(\theta)}=\theta q(\theta) c_{0}^{-1 /(1+\mu)}$, and $\tilde{\gamma}=\gamma c_{0}^{\alpha /(1+\mu)(1-\alpha)}$. Since the arrival rate of contacts for workers is determined by both $e(x)$ and $\theta q(\theta)$, these normalizations are possible. We cannot distinguish an economy with high $e(x)$

\footnotetext{
${ }^{7}$ Shimer (2005) estimated that the elasticity with respect to a vacancy equals 0.28 by calculating the elasticity of the job finding rate with respect to the vacancy-unemployment ratio. However, with on-the-job search, market tightness is no longer equal to the vacancy-unemployment ratio, so this is not the appropriate value. In the model, employed workers contact vacancies at the same rate as unemployed workers, so market tightness is proportional to the number of vacancies.
} 
and $\theta q(\theta)$ low from one with low $e(x)$ and high $\theta q(\theta)$ as long as the cost of posting vacancy $\gamma$ is adjusted appropriately. This means that $c_{0}$ is inherently undetermined, so we set it equal to one. We calibrate the parameter of cost function $\mu$ by targeting the observed monthly job-to-job transition rate of $2.2 \%$, based on Nagypál (2008).

In order to pin down the scale parameter $m_{0}$ and the vacancy cost $\gamma$, we combine the monthly job finding rate, $f=0.45$, estimated in Shimer (2005) with a mean value of the vacancyunemployment ratio of 0.72 , which is reported by Pissarides (2009).

Following Nagypál (2005), we assume that the idiosyncratic productivity distribution $F$ is a truncated exponential in the range $[0,1]$, so that

$$
F(x)=\frac{1-\exp (-\nu x)}{1-\exp (-\nu)}
$$

The spread of distribution of idiosyncratic productivity affects the distribution of wages. By using a variety of data sources, Hornstein, Krusell and Violante (2007) estimate a measure of wage dispersion, the mean-min wage ratio between 1.5 and 2 . We determine the parameter $\nu$ by targeting the mean-min wage ratio of 1.75 , which lies in the middle of the estimation result of Hornstein et al. (2007). Moreover, we can assume $G=F$.

We now determine the unemployment flow utility parameter $z$. In calibrations of search and matching models, this parameter has been the subject of some discussion. ${ }^{8}$ For the benchmark case, we set $z$ equal to the replacement rate 0.71, estimated by Hall and Milgrom (2008). It includes both unemployment insurance and the value of time. ${ }^{9}$

It remains to select $\lambda$. The average unemployment rate in the US is $6 \%$. We choose the rate of arrival of the idiosyncratic shocks $\lambda$ to match the unemployment rate. The parameter values are summarized in Table 2.

\footnotetext{
${ }^{8}$ Shimer $(2005)$ sets $z / \bar{w}$ equal to 0.4 in order to capture unemployment benefits. Hagedorn and Manovskii (2008) argue that Shimer's choice of the value of opportunity cost of employment is too low because it does not allow for the value of leisure, home production, as well as unemployment benefits. They calibrate the opportunity cost of employment and the worker's bargaining power to match the observed cyclical response of wages and average profit rate. Their results are $z=0.955$ and $\beta=0.052$. Mortensen and Nagypál (2007) criticize Hagedorn and Manovskii (2008) for using these parameters because these parameters yield workers a gain of $2.8 \%$ in flow utility by going from unemployment to employment.

${ }^{9}$ Hall and Milgrom (2008) use utility parameter values based on the empirical literature on household consumption and labor supply and reports of the effective replacement ratio to estimate the value of $z$.
} 


\subsection{Results}

Some of the model solutions under the chosen parameter values are reported in Table 3 . The model is able to match quite closely the target moments. ${ }^{10}$ The reservation productivity $R$ is 0.078. This gives an endogenous separation of approximately $35 \%$ per year, which is consistent with what is observed in the U.S. data. The value of the reservation productivity is lower than the value of unemployment flow utility. Thus, unemployed workers are willing to match with a job with a low productivity. This result comes from the option value of working. The average wage in the economy is 0.214 , and the replacement rate $(z / \bar{w})$ is 0.704 , which is very close to our target moment.

In Figure 4, we plot the initial density of the distribution of initial idiosyncratic productivity draws $F$ and the endogenous equilibrium distribution of employed workers across productivity $H$. Since employed workers move from low to high productivity jobs, the equilibrium distribution of employed workers $H$ first-order stochastically dominates the distribution of initial productivity $F$.

The equilibrium search intensity as a function of idiosyncratic productivity is plotted in Figure 5. The search intensity of workers is decreasing with productivity. Thus, the search effort of unemployed workers is higher than that of employed workers. In the literature, it is reported that only a small fraction of employed workers searches for jobs intensively, and these actively searching employed workers account for a small portion of job-to-job transitions. In our model, the optimal search intensity of an unemployed worker is 0.297. Employed workers in a job with productivity $x=0.086$ search for jobs with an intensity level that equals $80 \%$ of the intensity level of unemployed workers. In equilibrium, about $99 \%$ of employed workers are above this productivity. Thus, the model can match the fact that the few employed workers actively search for a job.

\subsection{Productivity growth and the labor market}

We now calculate steady-state responses to an increase in the growth of disembodied technological progress. Figure 6 reports the results.

A faster rate of productivity growth reduces the separation rate, which matches the data. This implies that the introduction of on-the-job search enables the endogenous job separation model with DTP to explain the negative relationship between productivity growth and the separation rate, and thus the negative relationship between growth and unemployment.

\footnotetext{
${ }^{10}$ Although the fit with the target moments is very good, it is not perfect. This is due to some coarseness in the grid over which we evaluated the model.
} 


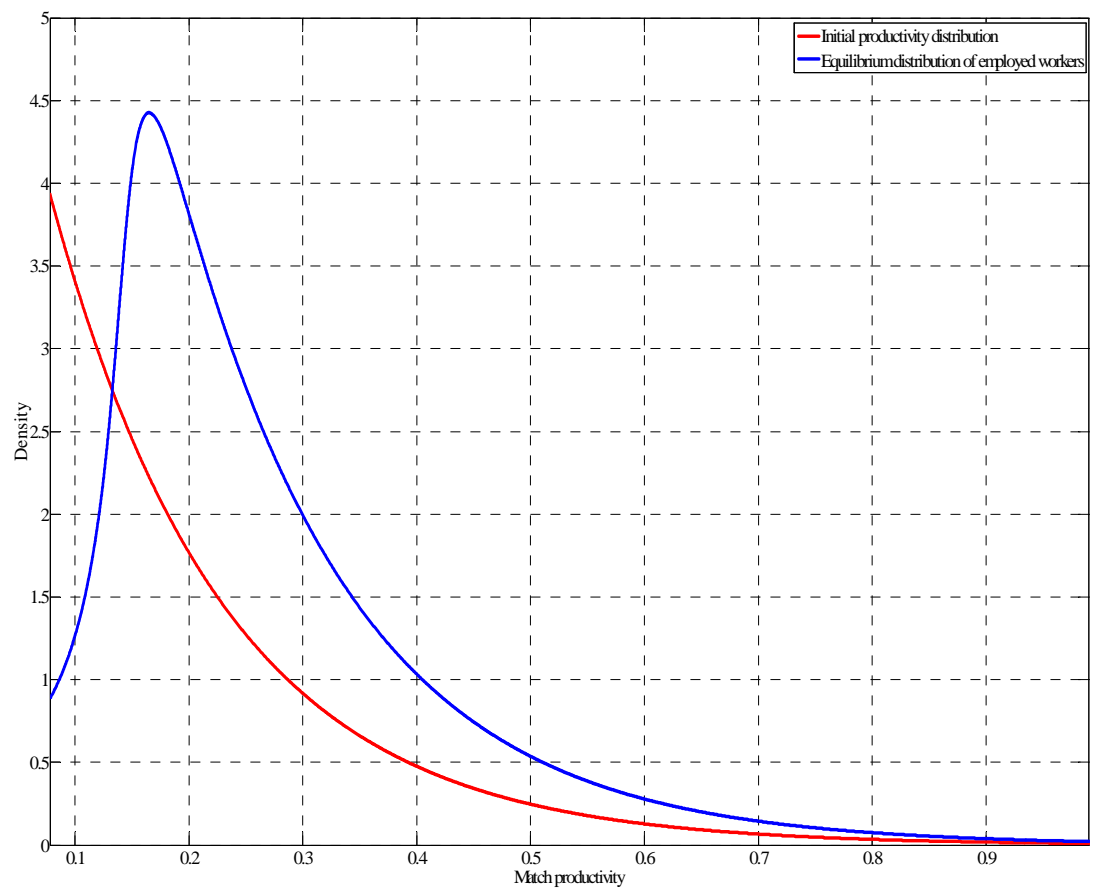

Figure 4: Distribution of employed workers 


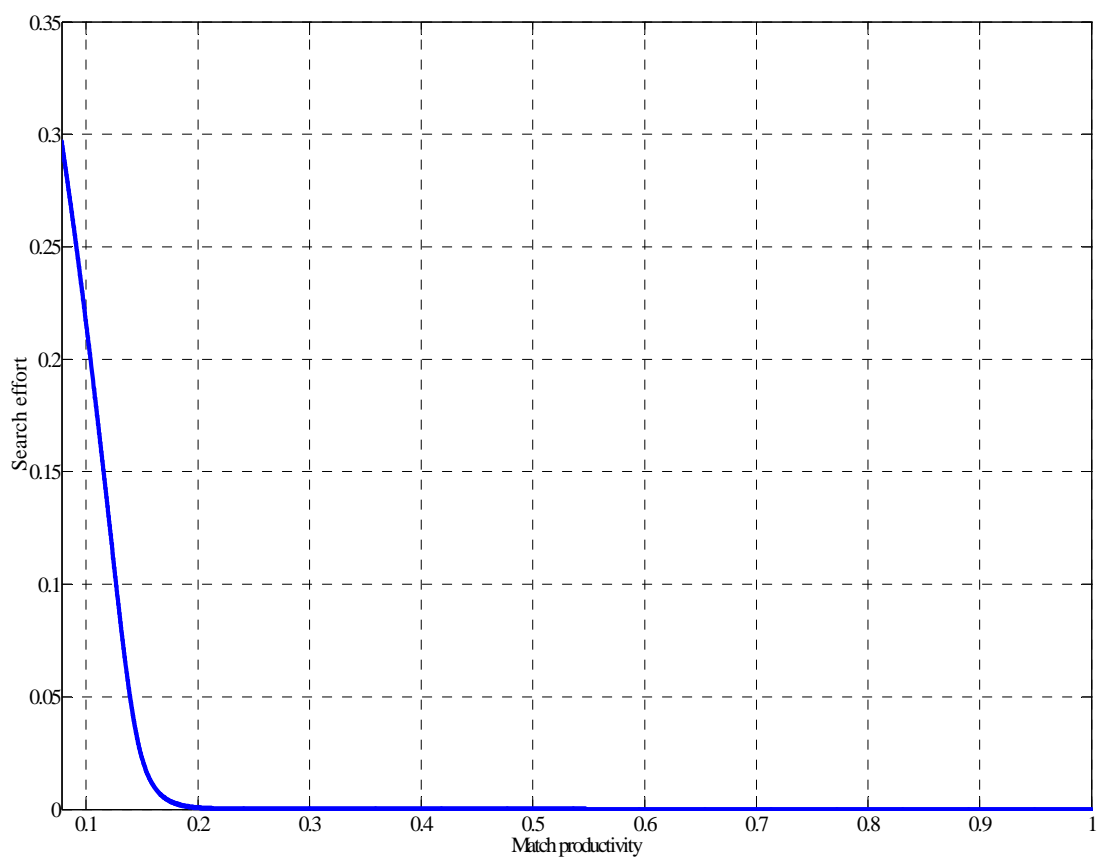

Figure 5: Optimal Search Intensity 

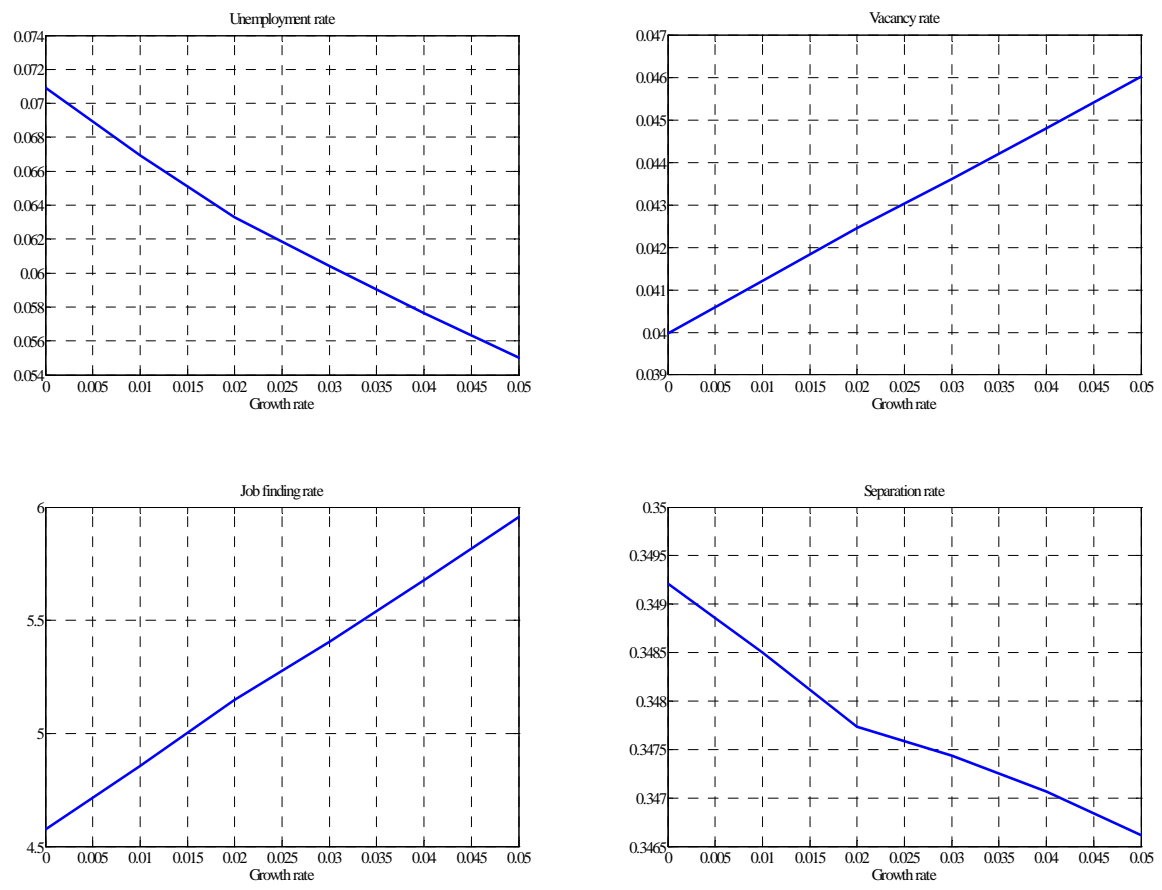

Figure 6: Comparative statics for disembodied technical change $g$. 
The mechanism of our model can be understood by comparing to the standard endogenous job separation model with DTP. In the standard model, the impact of disembodied technological progress on the separation rate is ambiguous because there are two counteracting effects: the labor hoarding effect and the outside option effect. The labor hoarding effect reduces the value of the reservation productivity $R$ because the option value of a match is an increasing function of $g$. On the other hand, the outside option effect, identified by Prat (2007), raises the value of the reservation productivity $R$. Since faster technological progress increases the job finding rate through the capitalization effect, workers have better outside opportunities and so ask for higher wages. This reduces the value of the match, and the firm raises the reservation value of productivity $R$. When the labor hoarding effect dominates the outside option effect, productivity growth reduces the reservation value and thus the separation rate. As seen in the next section, under plausible parameter values, the model without on-the-job search fails to generate a negative impact of productivity growth on the separation rate. Furthermore, the model generates a positive impact of productivity growth on unemployment rate.

Faster productivity growth reduces the separation rate in our model because the outside option effect is weakened due to on-the-job search. In the model, workers in firms with low productivity jobs search on the job. Some of the benefit from on-the-job search is shared with the firm through the wage. This makes otherwise unproductive jobs productive enough to survive, leading to decreased separation when the rate of productivity growth increases.

The job finding rate and the vacancy rate increase with disembodied technological progress. Since a higher rate of productivity growth increases the return from creating a job, firms have a greater incentive to open vacancies. Hence, the job finding rate of workers rises. This is because the cost of creating a vacancy is paid at the start but the profits accrue in the future. When the rate of productivity growth increases, all future income flows are discounted at lower rate, so firms are encouraged to create more vacancies. This effect is well-known as the capitalization effect (Aghion and Howitt, 1994, 1998; Pissarides, 2000).

In addition to the capitalization effect, the incorporation of on-the-job search generates more job creation as DTP increases. In a model without on-the-job search, all job creation has to be fed from the pool of unemployed, which is quickly exhausted in a high growth economy. Instead, in our model, when productivity growth is high, increasing search activity by employed workers expands the pool of potential hires for firms. This induces more job creation. This mechanism is similar to what we see in the recent literature of the search and matching model in the business cycle, which finds on-the-job search amplifies the effect of productivity shocks on unemployment (Nagypál, 2007; Krause and Lubik, 2006). Thus, our results suggest that on-the-job search is not only relevant to the business cycle properties of the search and matching model but also to its 
long-run predictions.

To summarize, the incorporation of on-the-job search gives rise to two new channels through which a faster productivity growth may reduce unemployment: an increased job finding rate and a reduced separation rate. Both factors leads to lower unemployment when productivity growth increases. Furthermore, incorporating on-the-job search substantially improves the performance of the search and matching model in accounting for the size of the impact of growth on unemployment. In the standard exogenous job separation matching model with DTP, a $1 \%$ decrease in growth rate increases the unemployment rate by less than $0.01 \%$. This is far below the estimated magnitude of the impact of growth on unemployment in the literature. Blanchard and Wolfers (2000) estimate that a $1 \%$ decline in the growth rate leads to a $0.25-0.7 \%$ increase in the unemployment rate. Pissarides and Vallanti (2007) find the effect to be $1.3 \%$ to $1.5 \%$. Our result shows that a one percentage point decline in the rate of productivity growth increases the unemployment rate by $0.32 \%$. Thus, our model generates not only an empirically consistent sign of the effect, but also a larger size of impact of growth on unemployment than the standard model.

The model predicts an increase in job-to-job transitions as productivity growth increases. Technological progress affects job-to-job transitions through three channels. First, the capitalization effect increases the job finding rate of employed workers. Second, a faster rate of productivity growth increases the net benefits of on-the-job search. Third, a faster rate of productivity growth increases the number of employed job seekers.

It is also important to understand how the optimal search intensity of workers changes in response to productivity growth. In order to illustrate this, in Figure 7 we plot the equilibrium search intensity as a function of the idiosyncratic productivity. Figure 7 shows that the optimal search intensity is higher when productivity growth is high. This is because a faster rate of productivity growth increases the benefits of on-the-job search and reduces its cost.

Figure 8 plots the effect of productivity growth on the equilibrium distribution of employed workers. A change in productivity growth affects the characteristics of the distribution in two ways. Since faster productivity growth reduces the reservation value of productivity, the support of the endogenous distribution of employed workers becomes larger. Also, the composition of employed worker in jobs with high productivity increases. Figure 8 shows that with faster productivity growth, more employed workers are in jobs with high productivity. 


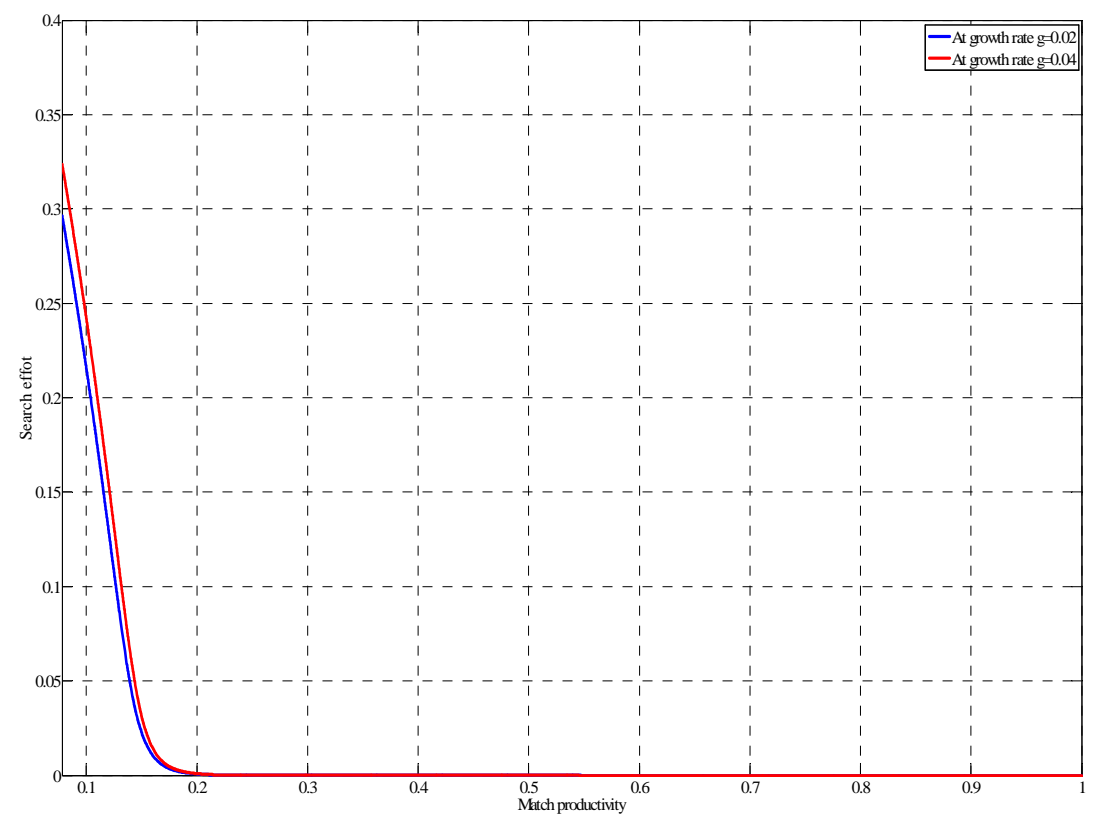

Figure 7: The effect of productivity growth on optimal search intensity

\section{Discussion}

This section evaluates the robustness of our results in the previous section. First, we discuss the sensitivity of our results to our choice of parameter values. Then, we assess whether or not the results of our model crucially depends on the incorporation of on-the-job search.

\subsection{Sensitivity analysis}

In our model with on-the-job search, a faster productivity growth reduces the separation rate, leading to a fall in the unemployment rate. We now study how our results vary with the value of the worker's bargaining power $\beta$, and the flow value of unemployment $z$. When we change these parameters, we also re-calibrate parameters $m_{0}, z, \gamma, \mu, \lambda$, and $\nu$ in order to maintain our calibration target values.

To be compled soon. 


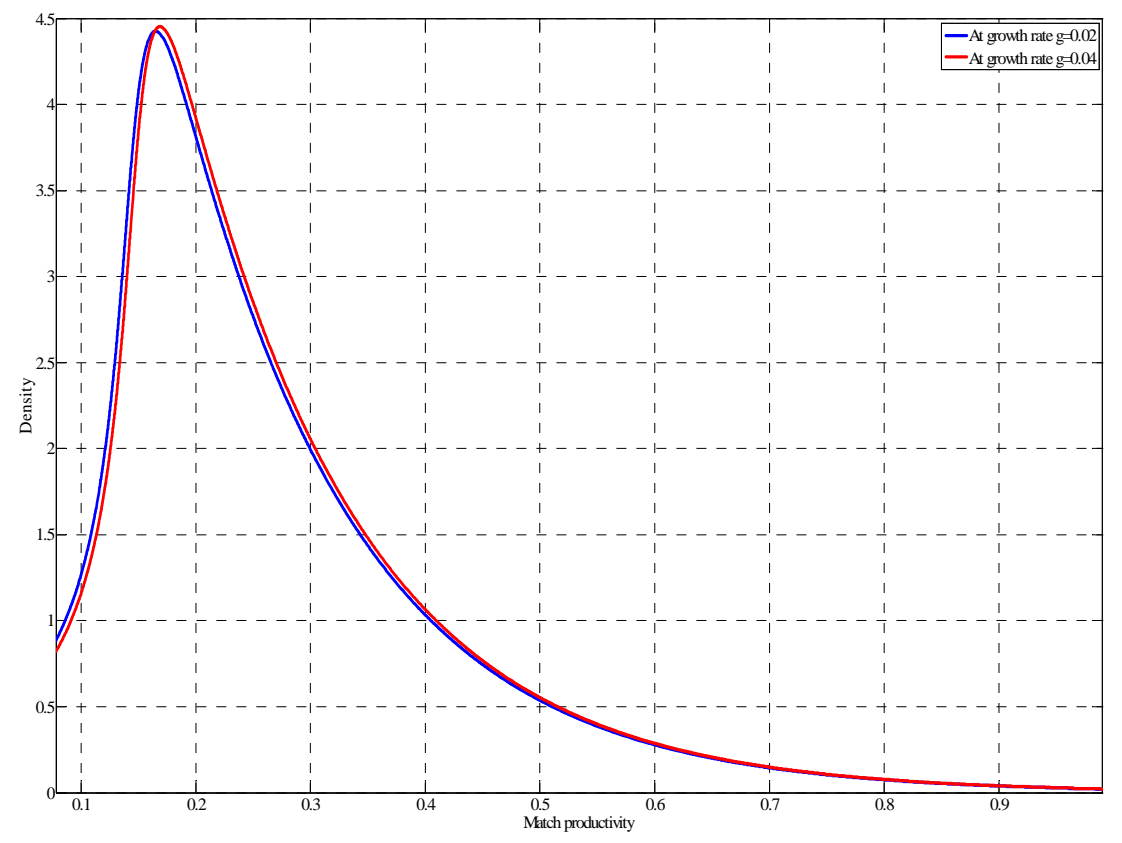

Figure 8: The effect of productivity growth on the distribution of employed workers 


\subsection{The role of on-the-job search}

Here we assess the contribution of on-the-job search to this key result by examining a model without on-the-job search. This experiment allows us to determine whether or not the results of our model crucially depend on the incorporation of on-the-job search.

Now we consider an endogenous job separation model with productivity growth. The basic structure of the model is the same to that of Mortensen and Pissarides (1994). To analyze the impact of productivity growth on unemployment, we incorporate disembodied technological progress into the model of Mortensen and Pissarides (1994). Furthermore, to facilitate comparison between our original model and this model, we assume that an initial value of idiosyncratic productivity $x$ is drawn from a distribution $F$, and subsequently let $\{x\}$ be a jump process characterized by arrival rate $\lambda$ and a distribution of new realizations $G$. Note that in Mortensen and Pissarides (1994), all new jobs are created at the highest productivity. The details of the model can be found in Appendix.

Without on the job search, the following job creation and job destruction conditions determine endogenous variables $\theta$ and $R$ :

$$
\frac{\gamma}{q(\theta)}=\frac{(1-\beta)}{r+\lambda-g} \int_{R}^{\bar{x}}\left(x^{\prime}-R\right) d F\left(x^{\prime}\right)
$$

and

$$
0=R-z-\frac{\beta \theta \gamma}{1-\beta}+\frac{\lambda}{r+\lambda-g} \int_{R}^{\bar{x}}\left(x^{\prime}-R\right) d G\left(x^{\prime}\right) .
$$

Given the equilibrium $\theta$ and $R$, the unemployment rate is determined by

$$
u=\frac{\lambda G(R)}{\lambda G(R)+\theta q(\theta)[1-F(R)]} .
$$

Note that in the model without on-the-job search, the labor market tightness $\theta$ is equal to the vacancy-unemployment ratio. The job finding rate is $\theta q(\theta)[1-F(R)]$, and the separation rate is $\lambda G(R)$.

We examine the impact of disembodied technological progress on labor market variables. Totally differentiating (17) and (18) shows that labor market tightness is an increasing function of $g$. The intuition is that faster growth raises the returns to job creation, so firms are encouraged to post more vacancies, resulting in higher labor market tightness. When the match separation is exogenously determined, faster productivity growth raises the job finding rate, lowering unemployment. However, once endogenous job separation is incorporated, the impact of DTP on unemployment rate is ambiguous. We can see this by looking at Figure 9. The locus of the pairs of $\theta$ and $R$ that satisfies the job creation condition (17) is a downward sloping curve JC over $\theta R$-space. On the other hand, the locus of the pairs of $\theta$ and $R$ that satisfies the job destruction 


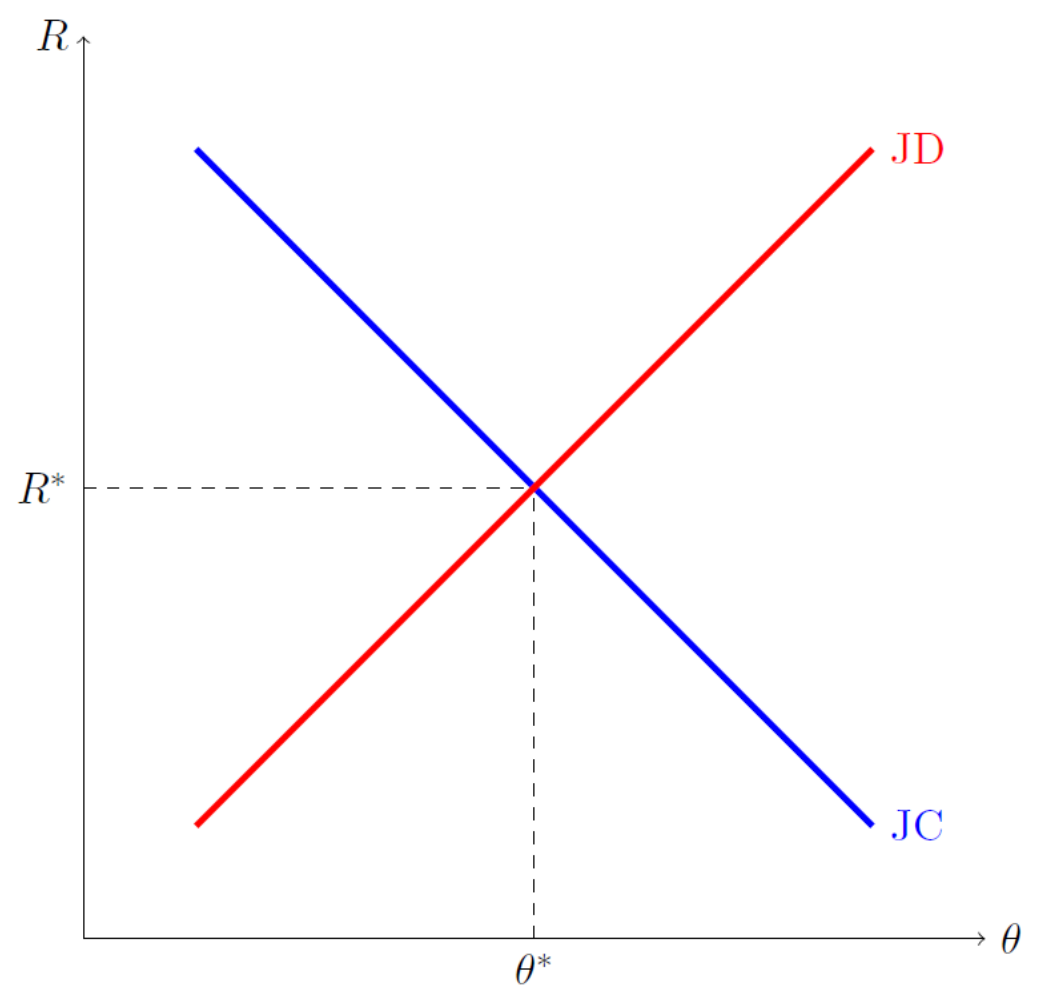

Figure 9: Job creation and job destruction curves in $\theta R$-space.

condition (18) is an upward sloping curve JD on the same plane. The intersection of the JC and the JD curves determines the equilibrium $\theta$ and $R$. When the productivity growth rate $g$ increases, the JC curve shifts upward and the JD curve shifts downward. Thus, while labor market tightness $\theta$ unambiguously increases, the reservation productivity $R$ may either increase or decrease. Hence, job finding and separation rates may increase or decrease. ${ }^{11}$

The ambiguity is due to a higher workers' outside option from a higher labor market tightness. Since faster productivity growth increases market tightness, workers have better outside opportunities and so ask for higher wages. This reduces the value of the match, and the firm raises the reservation value of productivity $R$. This effect is identified by Prat (2007) as the outside option effect. On the other hand, a faster productivity growth increases the option value of the match, leading to a fall in the reservation productivity. This effect is called the labor hoarding effect. When the outside option effect dominates the labor hoarding effect, a faster productivity growth increases the reservation value of productivity, and thus the separation rate.

\footnotetext{
${ }^{11}$ Notice that the separation rate is increasing function of the reservation productivity $R$, and the job finding rate is increasing in the market tightness $\theta$ but decreasing in $R$.
} 
The impact of DTP on the separation rate can be understood by examining the job destruction condition. Total differentiation of (18) yields

$$
\frac{d R}{d g}=\left(\frac{r+\lambda-g}{r+\lambda F(R)-g}\right) \frac{\beta \gamma}{1-\beta} \underbrace{\frac{d \theta}{d g}}_{(+)}-\frac{\lambda \int_{R}^{\bar{x}}\left(x^{\prime}-R\right) d G\left(x^{\prime}\right)}{[r+\lambda F(R)-g](r+\lambda-g)} .
$$

The first term and the second term of the RHS capture the outside option effect and the labor hoarding effect, respectively. We can see that the sign of the impact of productivity growth on the separation rate depends on which effect dominates. When the labor hoarding effect dominates, faster productivity growth reduces the value of the reservation productivity. Then, the separation rate falls and the job finding rate rises, leading to a lower unemployment rate. On the other hand, when the outside option effect dominates, faster productivity growth increases the value of the reservation productivity, and thus separation rate. The job finding rate may increase or decrease. When the job finding rate falls, the unemployment rate rises. When the job finding rate increases, the impact of a faster growth on unemployment is ambiguous.

We quantitatively analyze this model to help clarify these ambiguities. Basic parameter values are the same as those used before. We normalize to the time period to be one year and choose a discount rate $r$ of $5 \%$. Again, we normalize the average productivity to be one. We set $g$ to 0.02 . The matching function is assumed to be Cobb-Douglas, and the matching constant $m_{0}$ is chosen to match the vacancy filling rate given the elasticity with respect to unemployment $\alpha$. Similar to before, the cost of posting a vacancy $\gamma$ and the arrival rate of idiosyncratic shocks $\lambda$ are chosen to match the job finding rate and the average unemployment rate.

It remains to select the elasticity of matching function $\alpha$, workers' bargaining power $\beta$, and the value of non-market activity $z$. First, we follow the calibration strategy proposed by Shimer (2005), and set $\alpha=\beta=0.72$ and $z=0.4$. The parameter values under this calibration strategy are reported in column (1) of Table 4. In the second calibration strategy, we use the value of non-market activity chosen by Hall and Milgrom (2008) and set $z$ to be 0.71 , and the elasticity parameter $\alpha$ is set to 0.5 , as suggested by the matching function estimates in Petrongolo and Pissarides (2001). The workers' bargaining power $\beta$ is set to 0.5 to internalize the search externalities. The parameter values under this calibration strategy are reported in column (2) of Table 4. Lastly, we use the calibration strategy proposed by Hagedorn and Manovskii (2008), and set $\beta=0.052$ and $z=0.955$. Also, we use their parameter value for the elasticity of the matching function, i.e., $\alpha=0.455$. Parameter values chosen by this calibration strategy are reported in column (3) of Table 4.

Again we perform comparative static exercises by calculating the steady-state responses to an increase in the productivity growth rate. Figure 10 reports the results of this experiment. 

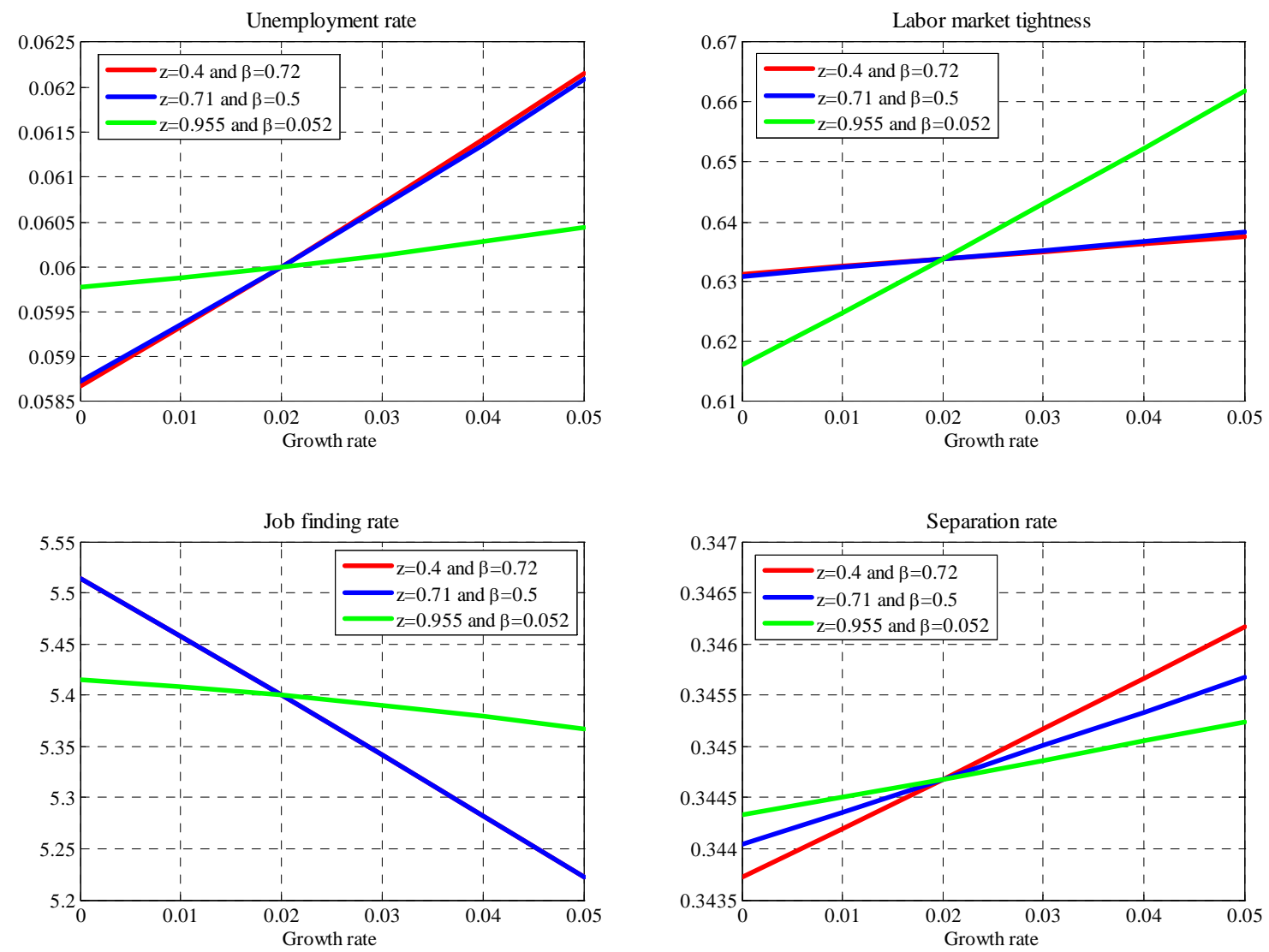

Figure 10: Comparative statics for disembodied technical change $g$ in the generalized MortensenPissarides model with disembodied technological progress. 
We see a positive relationship between the productivity growth rate and the separation rate. This is because the outside option effect prevails over the labor hoarding effect. This result is not consistent with the empirical negative relation between long-run productivity growth and the separation rate. We use various parameter values and find that this is more likely to be the rule than an exception. Thus, an endogenous job separation model with productivity growth tends to generate a positive impact of productivity growth on the separation rate.

It is worth noting that although faster productivity growth increases the labor market tightness, it reduces the job finding rate. This is because a faster growth increases the reservation value $R$.

The overall effect of DTP on the unemployment rate is determined by interactions between the job finding rate and the separation rate. Since faster productivity growth reduces the job finding rate and increases the separation rate, the unemployment rate rises. Calibrating the model shows that a one percentage point rise in the productivity growth rate leads to a $0.013-0.07 \%$ increase in the unemployment rate. Thus, the model fails to generate the empirically consistent sign of the impact of productivity growth on unemployment.

Our result in this section is similar to that of Prat (2007). Prat (2007) considers the endogenous job separation model in which the job's idiosyncratic productivity follows a Geometric Brownian Motion. He demonstrates that the effect of productivity growth rate on unemployment depends on the worker's value of non-working $z$ and the workers' bargaining power $\beta$. He shows that when $z=0.4$ and $\beta=0.72$, as used by Shimer (2005) and others, higher growth rate increases the unemployment rate. However, when $z$ is large and $\beta$ is very small, as is used by Hagedorn and Manovskii (2008), higher growth decreases the unemployment rate. Our result in this section is stronger than this. In other words, for various parameter values of $z$ and $\beta$, the model generates the positive relationship between productivity growth rate and the unemployment rate.

This difference between results of our paper without on-the-job search and those of Prat (2007) comes from the assumption about the job's initial productivity. While the original Mortensen and Pissarides (1994) model assumes that the job's initial productivity starts at the highest productivity, the model in this section assumes that the job's initial productivity is drawn from the distribution $F$. Now we consider the case in which $F(x)$ is degenerate at $\bar{x}$. Again, we assess the quantitative property of the model by using three different calibration strategies. The calibrated parameter values are summarized in columns (4)-(6) of Table 4, and the result of quantitative comparative statics exercises is reported in Figure 11.

The impact of productivity growth on the unemployment rate depends on the parameter values of $z$ and $\beta$ as seen in Prat (2007). When $z$ is large and $\beta$ is very small, higher growth reduces the unemployment rate, which is consistent with the data. This result comes from an 

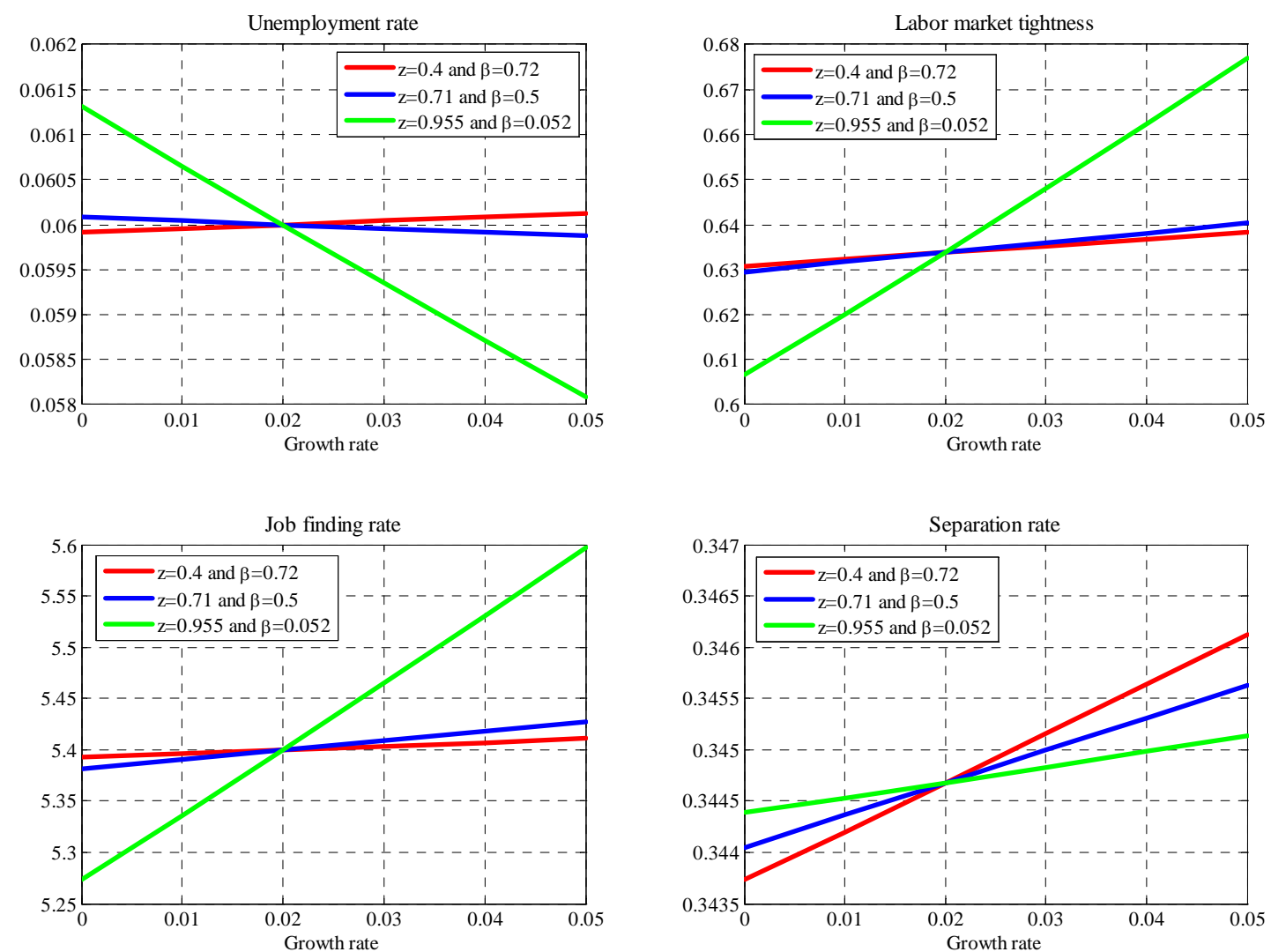

Figure 11: Comparative statics for disembodied technical change $g$ in the Mortensen-Pissarides model with disembodied technological progress. 
increased job finding rate due to the capitalization effect. When the job's initial productivity start at the highest value, the job finding rate $\theta q(\theta)$ does not depend on the reservation productivity. Hence, the higher labor market tightness due to the capitalization effect unambiguously increases the job finding rate. When $z=0.955$ and $\beta=0.052$, since the capitalization effect dominates the outside option effect, a higher growth rate reduces the unemployment rate. However, the impact of productivity growth on the separation rate is not consistent with empirical findings. In all calibration strategies, a higher growth rate increases the separation rate. This implies that the size of the outside option effect is not small, and endogenous job separation models with productivity growth cannot account for the empirical relationship between the long-run productivity growth and the separation rate.

\section{Conclusion}

This paper studies the impact of long-run productivity growth on the job finding rate, the separation rate, and unemployment rates in a search and matching model. By examining the long-run relationship between the productivity growth rate and labor markets variables in the U.S., we find that, while the job finding rate is positively correlated with the growth rate, there is a strong negative correlation between the separation rate and growth. Furthermore, we find that both job finding and separation rates contribute to overall unemployment variability in the longrun. These empirical findings suggest that productivity growth reduces the unemployment rate through not only increased job finding but also decreased separation.

In order to explain these empirical facts, we incorporate on-the-job search and endogenous search intensity into the endogenous job separation model of Mortensen and Pissarides (1994) with disembodied technological progress. The incorporation of on-the-job search gives rise to new channels through which faster growth may reduce unemployment, by reducing the separation rate and inducing more job creation. Our model demonstrates that faster productivity growth reduces the separation rate and increases the job finding rate, leading to lower unemployment. This result is consistent with empirical findings. Furthermore, the model not only generates an empirically consistent sign of the impact of growth on unemployment, but also generates a larger magnitude than the standard matching models with productivity growth.

A number of important issues remains for future research. One issue to be considered is the magnitude of the impact of productivity growth on unemployment. Although our model generates a larger magnitude than the standard models, it is still smaller than the estimated one in the data. Also, considering another wage determination mechanisms is an important issue. In the typical on-the-job search model, surplus sharing is not equivalent to the Nash bargaining solution 
because of the non-convexity of the Pareto set. A number of studies considers alternative wage determination mechanisms in a matching model with on-the-job search. However, most of these studies assume exogenous job destruction. To consider an alternative wage setting mechanism in an endogenous job destruction model with on-the-job search is a fruitful avenue for research. 


\section{References}

[1] Aghion, P., Howitt, P., 1994. Growth and unemployment. Review of Economic Studies 61, 477-494.

[2] Aghion, P., Howitt, P., 1998. Endogenous Growth Theory. MIT Press, Cambridge, MA.

[3] Baxter, M., King, R. G., 1999. Measuring business cycles: approximate band-pass filters for economic time series. Review of Economics and Statistics 81, 575-593.

[4] Ball, L., R. Moffitt., 2002. Productivity Growth and the Phillips Curve. In Krueger, A. B., and Solow, R. (Eds.), The Roaring Nineties: Can Full Employment be Sustained?. Russell Sage Foundation, New York.

[5] Blanchard, O.J., Wolfers, J., 2000. The role of shocks and institutions in the rise of European unemployment: The aggregate evidence. Economic Journal 110, 1-33.

[6] Bruno, M., Sachs, J. D., 1985. Economics of Worldwide Stagflation. Harvard University Press, Cambridge, MA.

[7] Cogley, T., Nason, J. M., 1995. Effects of the Hodrick-Prescott Filter on Trend and Difference Stationary Time Series: Implications for Business Cycle Research. Journal of Economic Dynamics and Control 19, 253-278.

[8] Fallick, B., Fleischman, C., 2004. Employer-to-employer flows in the U.S. labor market: The complete picture of gross worker flows. Federal Reserve Board, Finance and Economics Discussion Series Working Paper 2004-34.

[9] Fujimoto, J., 2009. Implications of General and Specific Productivity Growth in a Labor Market Matching Model. Manuscript. University of Tokyo.

[10] Fujita, S., Ramey, G., 2007. The Cyclicality of Separation and Job Finding Rates. forthcoming in International Economic Review.

[11] Hodrick, R. J., Prescott, E. C., 1997. Postwar US Business Cycles: An Empirical Investigation. Journal of Money, Credit, and Banking 29, 1-16.

[12] Christiano, L. J., Fitzgerald, S., 2003. The band pass filter. International Economic Review 44, 435-466.

[13] Hagedorn, M., Manovskii, I., 2008. The cyclical behavior of equilibrium unemployment and vacancies revisited, American Economic Review, 98(4), 1692-1706. 
[14] Hall, R. E., Milgrom, P., 2008. The Limited Influence of Unemployment on the Wage Bargain. American Economic Review 98(4), 1653-1674.

[15] Krause, M., Lubik, T., 2006. The cyclical upgrading of labor and on-the-job search. Labour Economics 13(4), 459-477.

[16] Michau, J-B., 2007. Creative Destruction with On-the-Job Search. CEP Discussion Paper No 835.

[17] Mortensen, D. T., 1994. The cyclical behavior of job and worker flows. Journal of Economic Dynamics and Control 18, 1121-1142.

[18] Mortensen, D. T., Pissarides, C. A., 1994. Job creation and job destruction in the theory of unemployment. Review of Economic Studies 61, 397-415.

[19] Mortensen, D. T., Pissarides, C. A., 1998. Technological progress, job creation, and job destruction. Review of Economic Dynamics 1, 733-753.

[20] Mortensen, D. T., Pissarides, C. A., 1999. Job reallocation and employment fluctuations. In: Woodford, M., Taylor, J.B. (Eds.), Handbook of Macroeconomics, vol. 1. Elsevier Science, Amsterdam, 1171-1227.

[21] Mortensen, D. T., Nagypál, E., 2007. More on Unemployment and Vacancy Fluctuations. Review of Economic Dynamics 10(3), 327-347.

[22] Muscatelli, V. A., Tirelli, P., 2001. Unemployment and Growth: Some Empirical Evidence from Structural Time Series Models. Applied Economics 33, 1083-1088.

[23] Nagypál, E., 2005. Labor-market fluctuations, on-the-job search, and the acceptance curve. Manuscript. Northwestern University.

[24] Nagypál, E., 2007. Labor-market fluctuations and on-the-job search. Manuscript. Northwestern University.

[25] Petrongolo, B., Pissarides, C. A., 2008. The Ins and Outs of European Unemployment. American Economic Review 98, 256-262.

[26] Pissarides, C. A., 1994. Search unemployment with on-the-job search. The Review of Economic Studies 61 (3), 457-475.

[27] Pissarides, C. A., 2000. Equilibrium Unemployment Theory, second ed. MIT Press, Cambridge, MA. 
[28] Pissarides, C. A., Vallanti, G., 2007. The Impact of TFP Growth on Steady-State Unemployment. International Economic Review 48, 607-640

[29] Postel-Vinay, F., 2002. The dynamics of technological unemployment. International Economic Review 43, 737-760.

[30] Prat, J., 2007. The impact of disembodied technological progress on unemployment. Review of Economic Dynamics 10, 106-125.

[31] Shimer, R., 2005. The cyclical behavior of equilibrium unemployment and vacancies. American Economic Review 95 (1), 25-49.

[32] Shimer, R., 2006. On-the-job Search and Strategic Bargaining. European Economic Review $50(4), 811-830$.

[33] Shimer, R., 2007. Reassessing the Ins and Outs of Unemployment. Manuscript. University of Chicago.

[34] Staiger, D., Stock, J., Watson, M., 2001. Prices, Wages and the U.S. NAIRU in the 1990s. In Krueger, A. B, Solow, R. (Eds.), The Roaring '90s: Can Full Employment Be Sustained. Russell Sage and Century Fund, New York, 3-60.

[35] Stock, J., Watson, M., 1999. Business Cycle Fluctuations in U.S. Macroeconomic Time Series. In: Woodford, M., Taylor, J. B. (Eds.), Handbook of Macroeconomics, vol. 1. Elsevier Science, Amsterdam, 3-64.

[36] Tripier, F., 2006. Sticky prices, fair wages, and the co-movements of unemployment and labor productivity growth. Journal of Economic Dynamics \& Control 30, 2749-2774. 


\section{Appendix}

\subsection{Generalized Mortensen and Pissarides (1994) Model}

In this appendix, we develop a generalized endogenous job separation model of Mortensen and Pissarides (1994) with disembodied technological progress. The basic structure of the model is the same as that of Mortensen and Pissarides (1994). While all new jobs are created at the highest productivity in Mortensen and Pissarides (1994), we assume that initial value of idiosyncratic productivity $x$ is drawn from a distribution $F$. We let $\{x\}$ be a jump process characterized by arrival rate $\lambda$ and a distribution of new realization $G$. Furthermore, in order to study the impact of long-run productivity growth on unemployment, we incorporate disembodied technological progress into the model. We use the same notations in our original model with on-the-job search to describe the generalized Mortensen and Pissarides (1994) model.

The value functions of firms and workers are

$$
\begin{aligned}
(r-g) \Pi(x) & =p x-w(x)+\lambda\left[\int \max \left[\left\langle\Pi\left(x^{\prime}\right), V\right\rangle d G\left(x^{\prime}\right)-\Pi(x)\right]\right. \\
r V & =-p \gamma+q(\theta)\left[\int \max \left[\left\langle\Pi\left(x^{\prime}\right), V\right\rangle d F\left(x^{\prime}\right)-V(x)\right]\right. \\
(r-g) W(x) & =w(x)+\lambda\left[\int \max \left[\left\langle W\left(x^{\prime}\right), U\right\rangle d G\left(x^{\prime}\right)-W(x)\right]\right. \\
(r-g) U & =p z+\theta q(\theta)\left[\int \max \left[\left\langle W\left(x^{\prime}\right), U\right\rangle d F\left(x^{\prime}\right)-U\right]\right.
\end{aligned}
$$

Given the free entry condition $V=0$, the surplus function $S(x)$ is characterized by

$$
(r+\lambda-g) S(x)=p x-p z+\lambda \int \max \left[\left\langle S\left(x^{\prime}\right), 0\right\rangle d G\left(x^{\prime}\right)-\theta q(\theta) \beta \int \max \left\langle S\left(x^{\prime}\right), 0\right\rangle d F\left(x^{\prime}\right) .\right.
$$

This implies

$$
S^{\prime}(x)=\frac{p}{r+\lambda-g}>0 .
$$

Since the surplus function is increasing in $x$, the firm and the worker will choose to form and continue any match that has an idiosyncratic productivity $x \geq R$. The reservation productivity is determined by $S(R)=0$. Using integration by parts and the free entry condition, we find the following job creation condition

$$
\frac{\gamma}{q(\theta)}=\frac{(1-\beta)}{r+\lambda-g} \int_{R}^{\bar{x}}\left(x^{\prime}-R\right) d F\left(x^{\prime}\right) .
$$

Evaluating (A1) at $x=R$ and using the above job creation condition, we have the following job destruction condition

$$
0=R-z-\frac{\beta \theta \gamma}{1-\beta}+\frac{\lambda}{r+\lambda-g} \int_{R}^{\bar{x}}\left(x^{\prime}-R\right) d G\left(x^{\prime}\right) .
$$


These two equations determine equilibrium values of $\theta$ and $R$. Given these values, the unemployment rate is determined by

$$
u=\frac{\lambda G(R)}{\lambda G(R)+\theta q(\theta)[1-F(R)]} .
$$


Table 1: Summary statistics: Correlation matrix

\begin{tabular}{ccccc}
\hline \hline & $g$ & $u$ & $f$ & $s$ \\
\hline$g$ & 1 & -0.659 & 0.310 & -0.842 \\
$u$ & - & 1 & -0.841 & 0.854 \\
$f$ & - & - & 1 & -0.447 \\
$s$ & - & - & - & 1 \\
\hline
\end{tabular}

Note: Correlation between the productivity growth rate $(g)$, the job finding rate $(f)$, the separation rate $(s)$, and unemployment rate $(u)$. All series are smoothed with band-pass filter with a cutoff frequency of 15 years. Sample covers 1948Q1-2005Q1. 
Table 2: Parameter values

\begin{tabular}{llcl}
\hline Parameter & Discription & Value & Source / Target \\
\hline$r$ & Discount rate & 0.05 & Data \\
$p$ & A general productivity parameter & 1.0 & Normalization \\
$m_{0}$ & Scale parameter of matching function & 26.14 & Job finding rate \\
$\alpha$ & Elasticity of matching function & 0.5 & Mortensen-Nagypál (2007) \\
$\beta$ & Workers's bargaining power & 0.5 & See text \\
$z$ & Flow value of unemployment & 0.151 & Hall-Milgrom (2008) \\
$\gamma$ & Cost of posting a vacancy & 1.216 & vacancy-unemployment ratio \\
$c_{0}$ & Scale parameter in search cost function & 1.0 & Normalization \\
$\mu$ & Parameter in search cost function & 0.102 & Job-to-job transition rate \\
$\lambda$ & Arrival rate of idiosyncratic shock & 0.866 & Unemployment rate \\
$\nu$ & parameter in idiosyncratic productivity distribution & 6.554 & The mean-min ratio \\
$g$ & The rate of productivity growth & 0.02 & Data \\
\hline
\end{tabular}


Table 3: Model solutions

\begin{tabular}{|c|c|c|c|c|c|}
\hline Variable & description & solution & Variable & description & solution \\
\hline$\theta$ & labor market tightness & 1.189 & - & job finding rate & 5.147 \\
\hline$R$ & reservation productivity & 0.078 & $Q$ & quit rate & 0.251 \\
\hline$u$ & unemployment rate & 0.063 & $J J$ & job-to-job transtions & 0.235 \\
\hline$v$ & vacancy & 0.042 & $E U$ & EU flows & 0.326 \\
\hline $\bar{e}$ & total amount of search effort & 0.035 & $\bar{w}$ & Average wage & 0.214 \\
\hline$e_{u}$ & search effor of an unemployed & 0.297 & - & Job destruction rate & 0.348 \\
\hline$\lambda G(R)$ & separation rate & 0.348 & - & Job creation rate & 0.348 \\
\hline
\end{tabular}


Table 4: Parameter values

\begin{tabular}{llccllll}
\hline Parameter & Interpretation & $(1)$ & $(2)$ & $(3)$ & $(4)$ & $(5)$ & $(6)$ \\
\hline$r$ & Discount rate & 0.05 & 0.05 & 0.05 & 0.05 & 0.05 & 0.05 \\
$m_{0}$ & Scale parameter of Matching function & 55.24 & 92.87 & 131.5 & 6.13 & 6.78 & 6.92 \\
$\alpha$ & Elasticity of Matching function & 0.72 & 0.5 & 0.455 & 0.72 & 0.5 & 0.455 \\
$\beta$ & Workers's bargaining power & 0.72 & 0.5 & 0.052 & 0.72 & 0.5 & 0.052 \\
$z$ & Flow value of unemployment & 0.4 & 0.71 & 0.955 & 0.4 & 0.71 & 0.955 \\
$\gamma$ & Cost of posting a vacancy & 0.317 & 0.387 & 0.540 & 0.335 & 0.551 & 0.401 \\
$\lambda$ & Arrival rate of idiosyncratic shock & 0.388 & 0.372 & 0.364 & 0.365 & 0.354 & 0.358 \\
$g$ & The rate of productivity growth & 0.02 & 0.02 & 0.02 & 0.02 & 0.02 & 0.02 \\
\hline
\end{tabular}

